\title{
Combining Momentum with Reversal in Commodity Futures
}

\author{
Robert J. Bianchi, Michael E. Drew, John Hua Fan* \\ Department of Accounting, Finance and Economics \\ Griffith Business School \\ Griffith University
}

Version: June 2015

\begin{abstract}
This paper examines profitable trading strategies that jointly exploit momentum and reversal signals in commodity futures. While the single-sort momentum strategies returns $11.14 \%$ per annum, on average, a consistent reversal pattern of momentum profits is pronounced from 12 to 30 months after portfolio formation. Combining the observed reversal pattern with the momentum signal, our double-sort strategy returns $20.24 \%$ per annum, which significantly outperforms single-sort strategies. The proposed strategy is robust to seasonality effects and sample adjustments in commodity futures. The profitability of the double-sort strategy cannot be explained by standard risk factors, term structure, market volatility, investor sentiment, data-mining or transaction costs, but appears to be related to global funding liquidity. As a consequence, the double-sort strategy in commodity futures may be employed as a portfolio diversification tool.
\end{abstract}

Keywords: Commodity Futures, Momentum, Reversal, Double-sort Strategy, Seasonality, Funding Liquidity

JEL classification: G13, G14

\footnotetext{
* Corresponding author. 170 Kessels Road, Nathan, Queensland 4111, Australia. Tel: +61 7373 54638; Fax: +61 7373 53719. E-mail: j.fan@griffith.edu.au (J. Fan)
} 


\section{Introduction}

Investments in commodities have become increasingly important due to their portfolio diversification benefits. Commodity returns are driven by factors that are very different from those affecting stocks and bonds, resulting in low correlations with traditional asset classes, and this helps reduce the overall risk associated with traditional portfolios (Bodie and Rosansky, 1980; Bodie, 1983; Ankrim and Hensel, 1993; Anson, 1999; Jensen et. al., 2000, 2002, Erb and Harvey, 2006; Gorton and Rouwenhorst, 2006; You and Daigler, 2010). Furthermore, these studies estimate the annualized rate of return of a long-only commodity futures portfolio at $10 \%$ to $14 \%$ per annum (depending on the sample period) which delivers mean returns similar to those of stocks. As a result, an unprecedented amount of capital has flowed into commodities investments during the 2005-2008 period (referred to by the media, World Bank and IMF as the 'Commodity Investment Boom’). ${ }^{1}$

Investors not only allocate capital to commodities over the long term, but studies by Fung and Hsieh (2001) and Spurgin (1999) show that alternative investment managers employ trendfollowing strategies in these markets. The idea of return continuation in commodities has led to the development of momentum studies in this literature. A limited number of momentum studies, including Miffre and Rallis (2007, MR thereafter) and Shen et. al., (2007), focus specifically on commodity futures. MR show that momentum strategies generate an average return of $9.38 \%$ per annum and conclude that the profitability of momentum strategies is not a compensation for bearing risks but appears to be related to commodity term structure information. Shen et. al., (2007) present supporting evidence; however, they argue that commodity momentum is more consistent with investor overreaction. Given the importance

\footnotetext{
${ }^{1}$ From 2003 to 2010, commodity related institutional investments have grown from less than \$20 billion to more than $\$ 250$ billion according to a Barclays Capital survey of over 250 institutional investors. Moreover, AUM (assets under management) for managed futures and CTAs has grown from $\$ 45$ billion to $\$ 334$ billion in the period of 2002-2012 (see http://www.barclayhedge.com/).
} 
of commodities in the investment management industry, the lack of research attention given to commodity futures presents a major limitation to our understanding of momentum in these markets.

This study examines profitable trading strategies that jointly exploit momentum and reversal signals in commodity futures. The single-sort momentum strategies, on average, return 11.14\% per annum. However, for the first time in the commodities literature, we document a consistent reversal pattern of momentum profits from 12 to 30 months after portfolio formation. By jointly combining the observed reversal effects and the momentum signal, our novel double-sort strategy returns $20.24 \%$ per annum, significantly outperforming the singlesort strategies. The profitability of the double-sort strategy cannot be explained by standard asset pricing factors, market volatility, investor sentiment, data-mining, transaction costs or commodities seasonality, but appears to be related to global funding liquidity.

This study makes three major contributions to the literature. First, our extensive post-holding analysis reveals that commodity momentum profits consistently reverse from 12 to 30 months after portfolio formation and trend back up again from 30 to 60 months. The findings imply that commodity momentum may be better explained in behavioral terms, but the market correction for overreaction (i.e. reversal) in commodity futures is more rapid than in the equities market, which typically takes up to five years after portfolio formation. ${ }^{2}$ However, the profit accumulation from 30 to 60 months also implies that commodity momentum is uniquely distinctive from that of the equities market. ${ }^{3}$

\footnotetext{
${ }^{2}$ Another possible explanation of the observed reversal pattern may lie within the term structure of commodity futures. MR conclude that momentum strategies buy backwardated contracts and short sell contangoed contracts and conjecture that 'commodity futures markets do not switch over horizons of $2-5$ years from backwardation to contango (or conversely)'. The conclusion of MR does not rule out the possibility that the switches could take place more quickly within 2 years.

${ }^{3}$ Shen et. al., 2007, p.253) also show similar findings despite that their analysis focuses only on one ranking period (2-month) and the first 30 months of the standard 60-month post-formation period. Thus, we argue that the findings of Shen et. al., (2007) are ambiguous and potentially incomplete.
} 
Second, we document that allocating wealth tactically towards medium-term winner but longterm loser commodities and medium-term loser but long-term winner commodities generates economic and statistically significant profits. The double-sort strategy substantially outperforms the single-sort strategies on a risk-adjusted basis. Furthermore, the low correlations between returns from double-sort strategies and those of traditional investments (stocks, bonds and currencies) suggest that the proposed strategy can be an important tool in portfolio diversification. Third, we demonstrate that global funding liquidity risk plays a vital role when momentum and reversal are being examined in a unified framework. The factor loadings in our study reveal that returns from the proposed strategy exhibit little exposure to standard risk factors, slope of term structure, market volatility and investor sentiment. However, the evidence suggests that the profitability of the combined strategy is at least partially related to global funding liquidity. A decomposition of returns reveals that the interactions between momentum and reversal exhibit a link with extreme global liquidity events. $^{4}$

Our study is also related to two strands of literature. First, the apparent profitability of the single-sort momentum and double-sort momentum/reversal strategy presents challenges to the random walk hypothesis, which asserts that past price movements do not indicate any form of future directions in price. Stevenson and Bear (1970), Cargill and Rausser (1975), Leuthold (1972) and Cochrane (1999) demonstrate that commodity futures prices do not follow random walks, and that profitable trading rules may be applied to exploit predictable price patterns in these markets. Our findings complement this literature by demonstrating that

\footnotetext{
${ }^{4}$ Asness et. al., (2013) show that momentum (value) is positively (negatively) related to liquidity risk only when these strategies are formed globally across asset classes. Moreover, a global multi-asset class momentum and value combination strategy is related to global liquidity risk. Our finding that single-sort momentum is not related to liquidity is consistent with Asness et. al., (2013) as we focus only on commodity futures. Since the reversal/contrarian signal in this study closely resembles the value strategy implemented by Asness et. al., (2013), our results reinforce their findings, given that the double-sort momentum and reversal strategy in commodity futures is related to global funding liquidity effects.
} 
profitable trading strategies can be developed using past commodity prices. While the random walk hypothesis is clearly rejected, the findings do not suggest the rejection of the more complex efficient market hypothesis (Fama, 1970). Although the profitability of the proposed strategy is unrelated to standard asset pricing factors, market volatility and sentiment, we cannot rule out the existence of an alternative risk-based framework that the literature has not identified to explain the findings. Second, our finding that cross-sectional commodity momentum is similar to equity momentum premium is related to recent studies (Novy-Marx, 2012; Moskowitz et. al., 2012; Asness et. al., 2013) which present evidence that momentum exists in all major asset classes. Asness et. al., (2013) also show that despite the very different market mechanisms, momentum and value seem to carry a common component across asset classes. In this study, we demonstrate that single-sort commodity momentum is indeed related to the momentum anomaly in the U.S. stock market.

The reminder of the paper proceeds as follows. Section 2 provides a description of the data sources. Section 3 reports the detailed performance of single-sort momentum strategies, postformation analysis and the reversal signal unique to the commodity futures market. Section 4 provides a detailed description of the construction of double-sort strategies, followed by discussions on strategy performance, robustness checks, factor loadings, transaction costs and diversification benefits. The paper provides concluding remarks in Section 5.

\section{Data}

This study employs data from the constituents of the S\&P GSCI (Standard and Poor's Goldman Sachs Commodity Index) and DJ-UBSCI (Dow-Jones UBS Commodity Index). The data on the GSCI constituents are available from December 1969 (January 1991 in the case of 
UBS). ${ }^{5}$ However, in the early part of the sample, a very limited number of commodities were traded with sufficient liquidity. To maintain a reasonable level of volatility, we require at least three commodities to be traded in both long and short portfolios. As a result, the sample period for the S\&P GSCI and DJ-UBSUBS data is January 1977 to December 2011 and January 1991 to December 2011, respectively. For these two periods, we obtain daily excess returns of 27 GSCI and 26 UBS commodity futures price time series. The end-of-month prices are used to construct the aggregated monthly time-series price. The GSCI data are obtained from Datastream International and the UBS data are sourced from Bloomberg. ${ }^{6}$

While the use of Datastream and Bloomberg is common in the commodity futures literature, the specific use of the GSCI and UBS individual futures data is limited. Because of contract maturity reasons, prior momentum studies have employed raw futures contracts to compile the continuous time-series price. To achieve this, the nearest or the next nearest futures contract is often selected to be the 'roll' contract. Thus, when a futures contract expires, the position is rolled over to the next contract in order to maintain a continuous exposure in the underlying commodity (Miffre and Rallis, 2007; Shen et. al., 2007; Fuertes et. al., 2010, 2015; Moskowitz et. al., 2012; Asness et. al., 2013). This study employs continuous commodity futures price series which are pre-constructed by the respective data provider. The use of preconstructed continuous commodity futures prices has been employed in the literature. For example, Wang and Yu (2004) and Marshall et. al., (2008) employ continuous commodity

\footnotetext{
${ }^{5}$ The S\&P GSCI and its constituents were first launched in 1991 (UBS from 1998). Prior data were back calculated by S\&P and Dow Jones.

${ }^{6}$ Compared to stocks, commodity markets exhibit three key advantages for the study of momentum. First, the trading costs of futures contracts are much lower than those of stocks. Lesmond et. al., (2004) estimate a cost of 2.3\% per trade, and Jegadeesh and Titman (1993) use a more conservative $0.5 \%$ per trade in the equities market. However, as Locke and Venkatesh (1997) and Marshall et. al., (2012) show, transaction costs in futures markets range from $0.0004 \%$ to $0.033 \%$ per trade. Second, short selling in the equities market is often subject to special constraints. In commodity futures, however, there are no such constraints to prevent the short-selling of commodities. Third, momentum strategies in the equities market require the purchase and sale of a large number of stocks across the entire market (or a segment of the market) which puts pressure on the net profit of momentum trades (Korajczyk and Sadka, 2004). Compared to the tens of thousands of stocks, the crosssectional size of commodity futures is only a tiny fraction of the stock market, thus the trading intensity necessary for commodity momentum strategies is reduced.
} 
prices from Datastream to examine reversal strategies and technical trading strategies, respectively. The continuous futures prices employed in this study are compiled through a series of roll-over procedures. However, the rolling approach is slightly different from those employed in prior studies. The GSCI and UBS data are constructed by gradually rolling from the expiring contract to the next nearest contract, as opposed to an immediate roll approach adopted in previous studies. The 'immediate roll' approach requires all positions in the expiring contract to be closed out on the same day when the new positions are opened in the next nearby contract (see Miffre and Rallis, 2007; Shen et. al., 2007 for details). However, rolling all positions on a single day is unviable and impractical for large pension funds as this behavior would result in an adverse price impact on the market. Instead, the 'gradual roll' procedure in our study defines a roll period from the $5^{\text {th }}$ to the $9^{\text {th }}\left(6^{\text {th }}\right.$ to $10^{\text {th }}$ in the case of UBS) day of each month, where the weights of positions in the expiring contact are gradually increased to the next futures contract. As a result, any price impact is gradually absorbed by the market during the roll period due to the gradual re-weighting scheme between the front and the back end futures contracts. ${ }^{7}$

The continuous price series employed in our study has three major advantages over the selfcompiled time series. First, GSCI and UBS data are much more accessible than the raw futures contracts. The S\&P GSCI and DJ-UBSCI data are widely used for performance evaluation and benchmarking in the commodities market, and these indexes and constituent data reflect the real returns available to large market participants such as pension funds. Second, both Standard and Poor's and Dow Jones impose rigorous quality control. The

\footnotetext{
${ }^{7}$ For example, on the first day of the roll period for a given commodity, the first nearby contract and the roll contract will take a weight of 0.8 and 0.2 , respectively. As time approaches to the end of the roll period, the weight will change to $0.6 / 0.4,0.4 / 0.6,0.2 / 0.8$ until the futures contract closest to expiry takes a zero weight and the position is completely rolled-over to the next nearby contract. The compiled time series futures price included in our sample uses only the nearest and the next nearest contracts as these roll contracts mitigate liquidity concerns over the futures contracts expiring in faraway months. See S\&P (2012, p.36) and Dow Jones (2012, p.38) for details on their contract roll weights.
} 
calculations of these indexes are monitored by index committees and advisory panels; thus it is rational to assume accuracy and reliability advantages over the self-compiled price series. Third, the individual futures contracts and positions are often more difficult to manage since many commodities are traded across different exchanges. The commodity indexes employed in this study are uniform, which makes the replicability of our results an additional advantage over the self-compiled futures data and returns.

Table 1 lists the commodity futures indexes included in this study by sector, along with their inception dates, ticker symbols and summary statistics. Panel A reports the GSCI data and Panel B presents the UBS data. Since the GSCI and UBS do not share the same commencement dates, the summary statistics are not directly comparable. It is important to note that we employ both datasets from 1991 to 2011 to evaluate the robustness of our findings.

\section{Momentum based single-sort strategies}

\subsection{Methodology}

The single-sort momentum strategy is constructed following Jegadeesh and Titman (1993, thereafter JT). At the beginning of each month $T$, all commodities (UBS and GSCI separately) are ranked based on their previous $J$ months of returns. Accordingly, all commodities are sorted into terciles: winners, middle and losers. ${ }^{8}$ The momentum portfolio is formed by taking long positions in the winner portfolio while short selling the commodities in the loser portfolio. These long and short positions are subsequently held for $K$ months until rebalancing. Importantly, JT and other studies in the equities literature skip the first month after portfolio formation due to the short-term reversal and bid-ask bounce effects

\footnotetext{
${ }^{8} \mathrm{JT}$ use deciles for break points in the US equity market; however, the number of commodities available for trading inevitability limits the choice of higher break points. It is for this reason that tercile portfolios are employed in this study.
} 
(Moskowitz and Grinblatt, 1999; Cooper et. al., 2004; Boni and Womack, 2006). Since momentum strategies in the commodities market do not suffer from the same problems, skipping the first month leads to inferior returns (Miffre and Rallis, 2007; Shen et. al., 2007; Fuertes et. al., 2010; Asness et. al., 2013). Thus, no months are skipped between the ranking and holding periods in this study. The conventional ranking $(J)$ and holding $(K)$ periods are 1 , 3, 6, 9 and 12 months, which allows for a maximum of 25 strategies (where Mom $\mathrm{J-K}_{\mathrm{K}}$ denotes momentum strategies), with the $J$ months ranking periods and $K$ months holding periods. For all single-sort momentum strategies with holding periods longer than one month, this study follows JT and constructs equal-weighted overlapping portfolios (see Fuertes et. al., 2010 for details).

While momentum studies focus predominantly on strategy return and statistical significance, this study also reports a suite of performance metrics that are widely used by industry practitioners. However, the limited space confines the number of strategies that can be presented. Thus, the study selects 13 out of the 25 best performing strategies for detailed analysis. The returns of the remaining 12 strategies are also statistically significant and these results are available upon request. This results in five strategies with the one-month holding period (1-1, 3-1, 6-1, 9-1 and 12-1), four strategies with the three month holding period (3-3, 6-3, 9-3 and 12-3), two strategies with the six month holding period (6-6 and 9-6) and two strategies with the nine month holding period (3-9 and 6-9).

\subsection{Strategy performance and risk adjustment}

Table 2 presents the performance of 13 single-sort momentum strategies. Panel A reports the results of the long (winners) portfolio, Panel B shows the short (losers) portfolio and Panel C reports the long-short (momentum) portfolio. Panel C shows that all long-short momentum strategies exhibit statistically significant profits. Panel C suggests that an active commodity 
futures fund that systematically buys the best and short sells the worst performing commodities earns an annual average return of $11.14 \%$ over the 1977 to 2011 sample period. $^{9}$ The passive long-only benchmark that equally weights all commodities over the same period returns 3.57\% per annum, whereas a passive fund that tracks the S\&P GSCI earns $4.07 \%$ per year. Panels A and B suggest that the long portfolios generate a significant return of $9.97 \%$ p.a., on average, whereas the short portfolios report an insignificant return of $-1.17 \%$ per annum. Consistent with Shen et. al., (2007) and Fuertes et. al., (2010), momentum profits are dominated by the long positions. This does not imply that the success of momentum strategies is merely due to the increase in commodities prices from 1977 to 2011 (See Figure 4 for explanations).

The single-sort momentum strategies significantly outperform the passive benchmark based on other industry return and risk measurements. However, this comes at a cost of bearing additional risks. In Panel C, momentum strategies exhibit an average standard deviation of $19.49 \%$ versus $13.86 \%$ per annum for the benchmark. Furthermore, the active strategies exhibit a marginally higher $95 \%$ value-at-risk (VaR) of $8.32 \%$ compared to $6.28 \%$ with the benchmark based on the normality assumption, but a much higher 99\% Cornish-Fisher VaR at $29.23 \%$ versus $16.32 \%$ when skewness and kurtosis are incorporated.

Due to large variations in return volatility between the active and passive strategies, the returns are normalized using risks for more sensible comparisons. Panel $\mathrm{C}$ shows that the additional risks that active strategies bear are well compensated for by the higher returns. The average Sharpe ratio of active strategies is 0.57 versus the 0.26 achieved by the benchmark. When comparing the downside volatility, the Sortino ratio also demonstrates significantly superior risk-adjusted performance over the passive benchmark.

\footnotetext{
${ }^{9}$ Single-sort momentum strategies based on different portfolio break-points (quartile, quantile, sextile and decile) report similar average returns.
} 
To mitigate the possibility of data-mining, we first test the performance of single-sort momentum strategies in sub-periods using the S\&P GSCI data. The results suggest that single-sort momentum strategies are also profitable in sub-periods 1977-1990 and 1991-2011, although on average, the profitability appears to have declined substantially in the second sub-sample. As an out-of-sample test, the same strategies are tested again based on the UBS dataset from 1991-2011. The results reveal that only 4 out of 13 strategies remain significant, with an average profit of $7.96 \%$ per annum. Nevertheless, the actively traded strategies from 1991 to 2011 continue to outperform the passive long-only benchmark based on both the GSCI and UBS data (these results are available upon request).

Due to the lack of a commonly used commodity pricing model, we follow MR in testing the systematic risk factors that explain commodity futures returns. Consistent with MR and Fuertes et. al., (2010), we find that the commodity (S\&P GSCI), equity (S\&P500) and bond market (Datastream US Government Bond) factors are successful at capturing the returns of the long and short portfolios ( $R^{2}$ of approximately 0.50 , on average). However, these factors appear to be extremely poor at explaining the variation of momentum portfolio returns. Overall, these findings suggest that single-sort momentum strategies in commodity futures do not reflect compensation for bearing systematic risks. ${ }^{10}$

\subsection{Momentum profit post-formation and the reversal signal}

Jegadeesh and Titman (2001) pioneered the post-holding analysis of momentum by examining the holding period returns of up to 60 months after portfolio formation. The 60month post formation period includes a holding period of 12 months (first year) and postholding periods from 13 to 60 months (second to fifth year). Lee and Swaminathan (2000) also examined the post-holding-period returns of trading volume based momentum strategies.

\footnotetext{
${ }^{10}$ In the interests of brevity, these results are not reported, but are available upon request.
} 
We employ the post-holding analysis in this study to test several alternative explanations of the profitability of momentum strategies. For example, the conservatism hypothesis (Barberis et. al., 1998) predicts that momentum profits will be zero in the post-holding periods. Furthermore, the overconfidence hypothesis (Daniel et. al., 1998) suggests that momentum profits will be negative in the long run and the CK hypothesis (Conrad and Kaul, 1998) predicts that momentum strategies will be profitable in any post-holding periods, and remain profitable indefinitely. ${ }^{11}$

Virtually no studies have investigated the post-holding-period return of momentum strategies in the commodity futures literature. However, Shen et. al., (2007) is an important exception. Shen et. al., (2007) provides a post-holding analysis but only up to 30 months after portfolio formation. They also employed a 2-month formation period as opposed to the more commonly used 6-month and 12-month periods. Therefore, we are concerned that the findings in Shen et. al., (2007) are insufficient to draw adequate conclusions. This section of our study provides a comprehensive analysis of the post-holding period return of single-sort momentum strategies in commodity futures.

Sorted by the ranking period $(J)$, the cumulative momentum profits in a post-formation period of up to 60 months are illustrated in Figure 1. Two sub-samples are presented in the full period from 1977 to 2011 with a cut-off point in 1991. We also calculate the same momentum strategies using the UBS data as a comparison and to ensure the robustness of our results. Regardless of ranking period, sample period or data source examined, the results in

\footnotetext{
${ }^{11}$ Barberis et. al., (1998) show that conservatism leads to investors' underreaction to information because of the underweighting of new information. However, the interpretation implies that momentum profits will be zero in the post-holding period since the information from the ranking period has been fully impounded in the price. Furthermore, Daniel et. al., (1998) argues that investors attribute successes to their own skill or talent more than is warranted. This interpretation implies that in the long run, momentum profits are negative because the overreaction in prices are eventually corrected as investors observe future news and realize their prior errors. Alternatively, Conrad and Kaul (1998) propose that cross-sectional differences in returns explain momentum profits. However, their interpretation implies that momentum strategies are profitable in any post-holding periods and remain profitable indefinitely.
} 
Figure 1 monotonously show that momentum profits peak at around month 11 . However, an extremely consistent reversal pattern is pronounced from month 12 to 28 , where momentum profits tend to become negative. At month 28, the average cumulative profit is around zero. One of the differences across the three periods is the magnitude of profits. It can be observed that the cumulative profits are stronger in the 1977-1990 period and the reversal is stronger in the 1991-2011 period. Also noticeably, the patterns in the UBS data are largely consistent with the GSCI data in the second sub-period. The patterns from month 1 to 30 in Figure 1 are consistent with Shen et. al., (2007).

Strikingly however, from month 30 to 60 , Figure 1 also monotonically highlights an upward direction in momentum profits in all ranking and sample periods using both GSCI and UBS data sources. No further reversal is observed before month 60 (except for the first subsample). These findings are largely inconsistent with the existing theories (conservatism, overreaction and the CK hypothesis) in the literature.

To check the robustness of the results, we also test whether the observed patterns are driven by seasonality effects. ${ }^{12}$ Figure 2 illustrates the cumulative return of momentum portfolios by excluding markets from each commodity sub-sector. In this figure, one commodity sector (i.e. agriculture, energy, livestock, precious metals and industrial metals) is removed at a time, which results in five sub-figures in total. In the interests of brevity, only $J=6$ is reported. ${ }^{13}$ The sub-sector results are remarkably consistent with the 'all-sector' results previously reported in Figure 1, in which momentum profits peak at month 11 and reverse from month

\footnotetext{
${ }^{12}$ A large body of literature has considered seasonality effects in commodity futures. As stated by Gorton and Rouwenhorst (2006), unlike stocks and other financial assets, commodities exhibit seasonality patterns. For example, all agricultural crop commodities undergo stages of development before harvesting. The climatic conditions during the growing period have significant impacts on the expected production levels and, hence, the equilibrium price. Thus, these prices are more volatile in months when the weather conditions are more unstable (Roll, 1984; Kenyon et. al., 1987 Milonas, 1991). Furthermore, the demands for energy vary substantially from season to season, hence the prices of energy commodities also tend to follow a seasonal pattern (Pardo et. al., 2002; Hunt et. al., 2003).

${ }^{13}$ The results of other ranking periods are consistent with $\mathrm{J}=6$ and are available upon request.
} 
12 to 30 , then continue to trend back up from months 30 to 60 . These results suggest that momentum profits in commodities are robust and are not dependent on a specific commodity sector or seasonality effects. Despite the consistent pattern across sub-figures, it appears that excluding agricultural commodities from the sample increases the magnitude of momentum and reversal in the post-formation period. Overall, the findings reveal that commodity momentum is highly persistent when longer formation periods (over 30 months) are employed. This discovery is the first to be documented in the commodity futures literature.

Based on months 1 to 30 only, Shen et. al., (2007) conclude that the results are consistent with behavioral models. However, this study argues that such a conclusion is ambiguous and incomplete. Jegadeesh and Titman (2001) show that a full reversal of momentum profits could take as long as five years after portfolio formation; therefore, the observed pattern over the first two and a half years in this study implies (a) the results are consistent with underreaction during the holding period and overreaction over the long run, but the market correction for overreaction in commodity futures is far more rapid (profits takes much less time to reverse) than in equity markets, or (b) the results are inconsistent with proposed behavioral explanations and the post-holding period return of momentum strategies in commodity futures is uniquely distinctive from those in equity markets.

The finding of a reversal effect has significant implications for the commodity futures literature. First, our results can be used to explain the findings of MR, in which they employ conventional contrarian strategies. In contrast to momentum strategies, the contrarian strategy buys losers and short sells winners over long periods and holds these positions for long periods of time to exploit the reversal pattern. ${ }^{14}$ Conventional contrarian strategies require 3

\footnotetext{
${ }^{14}$ This price reversal (also referred to as the 'mean reversion effect' or long-term return reversal) pattern was first documented by DeBondt and Thaler (1985). They find that long-term (three to five years) winner stocks in the U.S. markets tend to underperform and long-term loser stocks tend to outperform in the subsequent three to
} 
to 5 years of ranking and holding, as opposed to the 1 to 12 months required by momentum strategies. MR show that the contrarian strategies of DeBondt and Thaler $(1985,1987)$, Conrad and Kaul (1998) and Yao (2012) in the stock market do not yield significant profits in commodity futures. However, the evidence in Figures 1 and 2 hints that the contrarian strategies at conventional ranking and holding periods will not be profitable in commodity futures, because the reversal in commodities occurs within 2.5 years, which is more rapid than the 3 to 5 years needed by the conventional contrarian strategy found in the equities literature. Second, the observed reversal pattern aids in the construction of more-profitable momentum strategies. This is discussed in detail in the next section.

As a robustness check, single-sort contrarian portfolios were formed to test the strength of the reversal signal as a standalone strategy. Table 3 reports the performance of single-sort contrarian strategies using both the conventional (3-5 years) and shorter (1.5-3 years) ranking and holding periods. Consistent with MR, we fail to find any statistically significant results at conventional ranking and holding periods. Notably, portfolios constructed using shorter ranking and holding periods do not yield statistically significant results either. These results indicate that single-sort contrarian strategies in commodity futures do not add value compared to single-sort momentum strategies. The following section examines whether the reversal signal can be used to enhance momentum profits.

\section{Double-sort strategies: improving momentum with the reversal signal}

\subsection{Methodology}

Conrad and Kaul (1998) conclude that contrarian strategies perform well over long horizons (3 to 5 years) whereas momentum strategies perform better over short-to-medium horizons (1

five years. The DeBondt and Thaler (1985) contrarian strategy which buys loser stocks and short sells winner stocks has been shown to generate statistically significant profits over long periods of time. 
to 12 months) in the stock market. Moreover, Cooper et. al., (2004) show that UP market momentum profits do reverse significantly in the long run, and conjecture that 'when there is momentum, there is ultimately long-run reversal'. The claim is supported by Bloomfield et. al., (2009) in a laboratory market setting. Using data from all major asset classes, Novy-Marx (2012), Moskowitz et. al., (2012) and Asness et. al., (2013) also show that momentum profits tend to reverse, at least partially, over long post-holding periods. Balvers and $\mathrm{Wu}$ (2006) propose a parametric model that jointly exploits the reversal and momentum effects in international stock markets. They show that the combined strategy is indeed superior to the pure momentum strategy and conclude that return continuation tends to accelerate reversals while reversals tend to enhance momentum by strengthening the return continuation, which in turn, leads to an even more superior performance. Chen et. al., (2009) also show that return reversal can be used to enhance momentum in the U.S. and international stock markets. Malin and Bornholt (2013) show that momentum can be used to enhance the performance of long-term contrarian investment strategies. Serban (2010) also shows that the profitability of momentum strategies can also be improved by reversals in foreign currency markets.

This literature motivates us to construct a new strategy that aims to jointly exploit the observed momentum and reversal patterns in the commodity futures markets. At a glance, contrarian and momentum strategies do not seem to conflict with one another since they are profitable at different time periods. However, this seemingly appealing idea is problematic in terms of implementation. While the conventional momentum strategy ranks markets based on their prior 12 months of return, the contrarian strategy often requires a much longer ranking period. Since the long ranking period subsumes the medium-term momentum ranking period, integrating the two strategies becomes difficult. To solve this problem, we employ a doublesort strategy that builds on the single-sort momentum strategy described in Section 3 of the 
study. ${ }^{15}$ Unlike other studies that use double-sort strategies, our second sort does not require additional information other than the returns of commodity futures. Our momentum-reversal combination strategy is non-parametric; therefore, it is different from the parametric strategy of Balvers and Wu (2006).

First, we sort all commodities into terciles (winners, middle and losers) based on their past 1 , 3, 6, 9 and 12 months of return. Within each winners and losers portfolio, we further sort those commodities into two sub-portfolios based on their past 15, 18, 21, 24, 30, 36, 48 and 60 months of return. ${ }^{16}$ This would result in four portfolios in total, each with approximately four to five commodities: (1) medium-term winners that are long-term winners; (2) mediumterm winners that are long-term losers; (3) medium-term losers that are long-term winners; and (4) medium-term losers that are long-term losers. The double-sort strategy takes long positions in (2) and short positions in (3); for example, by taking 12 and 24 months as the first and the second sort, respectively. The motivation of the design is that commodities in the 12 months winners portfolio, but are also losers over 24 months, should have more upside potential than the 24 months winners in the same portfolio. Similarly, commodities in the 12month losers portfolio, but are also winners over 24 months, should have more downside potential than the 24-month losers in the same portfolio. ${ }^{17}$

The double-sort strategy is denoted as $\operatorname{Mom}_{J(1)}-\operatorname{Ctr}_{J(2)}$, where $\operatorname{Mom}_{J(1)}$ represents the first sort using momentum ranking periods, where $J(1) \in\{1,3,6,9,12\}$. $\operatorname{Ctr}_{J(2)}$ represents the second

\footnotetext{
${ }^{15}$ The double-sort strategy is not uncommon in the momentum literature. For example, Fuertes et. al., (2010) combine momentum with term-structure signals in the commodities market. Lee and Swaminathan (2000) combine momentum with trading volume in the equities market. Sagi and Seasholes (2007) combine momentum with firm-specific attributes.

${ }^{16}$ The 36, 48 and 60-month periods are conventional ranking periods for contrarian (reversal) strategies; therefore, we employ these periods for comparison with our 15, 18, 21, 24 and 30-month ranking periods.

${ }^{17}$ The look-back period for momentum and contrarian signals may be partially overlapping. When the overlapping period is skipped in the contrarian signal, double-sort strategies no longer dominate the single-sort momentum strategies. Thus, it is imperative to consider these overlapping months in the contrarian/reversal signal, as they provide important insights into the identification of commodities that are likely to experience stronger momentum in the future.
} 
sort using contrarian ranking periods, where $J(2) \in\{15,18,21,24,30,36,48,60\}$. Therefore, the double-sort procedure produces a maximum number of 200 strategies if the holding period $K$ changes, where $K \in\{1,3,6,9,12\}$. To keep the results manageable and presentable, we take the following steps. As shown in Table 2, the single-sort momentum strategies with a holding period of one month produce the strongest results in terms of profitability and statistical significance. ${ }^{18}$ Unlike stocks and other financial assets, most commodity futures have monthly or bimonthly futures expiring cycles where the nearest and the next nearest contracts are often the most actively traded markets. Since these contracts need to be rolled over anyway (for continuous exposures of commodity markets), it is practical to limit the investment period to one month. Thus, we focus on a holding period of one month for all double-sort strategies. Although the number of strategies has been reduced substantially, 40 strategies are still tested.

\subsection{Strategy performance}

Due to a large number of strategies (as a result of the second-sort), we first examine the overall performance of the proposed double-sort strategy visually. Figure 3 illustrates a 3D surface graph of the performance of 40 double-sort momentum-contrarian strategies. Panel A illustrates the annualized return whereas Panel B exhibits the associated $t$-statistics. Panels C and D plot the annualized standard deviation and Sharpe ratios, respectively. The $\mathrm{x}$-axis outlines the ranking periods for the second-sort reversal signal and the z-axis outlines the ranking periods for the first sort momentum signal. The y-axis reports the respective statistics in each panel. Overall, Figure 3 reveals that double-sort momentum-contrarian strategies generate stronger results when momentum ranking periods are longer and contrarian ranking periods are shorter. Strategies with first-sort ranking periods of 9 and 12 months appear to perform the best, generating the most economic and statistically significant profits, while at

${ }^{18} \mathrm{~K}=1$, on average, generates $13.35 \%$ p.a. versus $9.76 \%$ p.a. achieved by the rest. 
the same time exhibiting lower volatilities, with Sharpe ratios of over 0.70. Based on this observation, we focus on double-sort strategies with a 12-month momentum signal for the remainder of the paper.

Table 4 reports the performance of double-sort strategies benchmarked against the 12-month single-sort momentum strategy. ${ }^{19}$ Panels $\mathrm{A}$ and $\mathrm{B}$ show the long and short portfolios, respectively. Panel C reports the long-short portfolios. The first four strategies (i.e. $\mathrm{Mom}_{12-}$ $\mathrm{Ctr}_{18}, \mathrm{Mom}_{12} \mathrm{Ctr}_{24}, \mathrm{Mom}_{12}-\mathrm{Ctr}_{36}$ and $\mathrm{Mom}_{12}-\mathrm{Ctr}_{48}$ ) represent double-sort strategies with a 12month momentum signal as the first-sort and the 18, 24, 36 and 48-month reversal signal as the second-sort. In addition to the proposed momentum-contrarian strategies, we also test the performance of double-sort strategies by reversing the order of the first and second-sort signals (i.e. $\mathrm{Ctr}_{18}-\mathrm{Mom}_{12}$, $\mathrm{Ctr}_{24}-\mathrm{Mom}_{12} \mathrm{Ctr}_{36}-\mathrm{Mom}_{12}$ and $\mathrm{Ctr}_{48}-\mathrm{Mom}_{12}$ ) for robustness reasons.

The results in Panel $\mathrm{C}$ of Table 4 suggest that systemically allocating wealth towards 'medium-term winners but long-term losers commodities' and 'medium-term losers but longterm winners commodities’ generates statistically significant and economic profits (average $t$ statistics of 4.22 ). The $12-1$ momentum strategy returns $16.88 \%$ p.a. and the double-sort momentum-contrarian strategies, on average, achieve a staggering $20.24 \%$ p.a. (equivalent to $1.69 \%$ per month). ${ }^{20}$ Notably, double-sort strategies using 18 and 24 months contrarian signals achieve, on average, $23.43 \%$ p.a. versus the $17.04 \%$ p.a. generated by the conventional contrarian signal with ranks of 36 and 48 months. Clearly, the contrarian

\footnotetext{
${ }^{19}$ Due to space limitations, only strategies with $18,24,36$ and 48 months reversal signals are reported (36 and 48 months conventional ranking periods are included here for comparative purposes).

${ }^{20}$ It must be highlighted that the average annual return of $20.24 \%$ also comes with an average standard deviation of $27.57 \%$ and a maximum drawdown of $-49.95 \%$. We thank Terry Walter for his constructive comments.
} 
strategy as a second sort at unconventional periods (18 and 24 months) significantly improves the single-sort momentum strategy. ${ }^{21}$

The Mom $_{12}-\mathrm{Ctr}_{18}$ which generates $26.48 \%$ p.a. (equivalent to $2.2 \%$ per month) is the best performing strategy across the board. ${ }^{22} \mathrm{Mom}_{12}-\mathrm{Ctr}_{24}$ is the least profitable, yet still delivers 20.38\% p.a.. The maximum monthly gain and the 12-month rolling return tell the same story where the double-sort strategies, on average, earn higher returns. Furthermore, long portfolios in the combined strategies produce $14.12 \%$ p.a., on average, compared to $-6.12 \%$ for short portfolios and these ranges are much higher than the $13.02 \%$ and $-3.87 \%$ generated by the single-sort Mom12-1. These results demonstrate that momentum can be enhanced by the reversal signal. Furthermore in Table 4, when the momentum signal is used to enhance the reversal signal, the double-sort contrarian-momentum strategies also report statistically significant profits. However, the results show that contrarian-momentum strategies deliver $14.07 \%$ p.a., on average, and do not outperform the 12-month single-sort momentum strategy. This finding implies that while the contrarian strategies do not work, the profitability of contrarian strategies can be significantly improved by the momentum signal.

To consolidate the results of 100 possible strategies, Table 5 provides a summary of the best, worst and average performance of single-sort momentum, single-sort contrarian, double-sort momentum-contrarian and double-sort contrarian-momentum strategies across the entire

\footnotetext{
${ }^{21}$ To conserve space, we do not report the results for $\mathrm{J}(1)=1,3,6$ and 9. These results are available upon request. $\mathrm{Mom}_{9}-\mathrm{Ctr}_{\mathrm{J}(2)}$ strategies present consistent results with $\mathrm{Mom}_{12}-\mathrm{Ctr}_{\mathrm{J}(2)}$ strategies. However, strategies with $J(1)=1,3$ and 6 , although profitable and statistically significant, do not outperform the respective single-sort momentum benchmarks.

${ }^{22}$ Fuertes et. al., (2010) generate $21.02 \%$ p.a. by combining momentum with term-structure signals; Fuertes et. al., (2015) also report returns higher than $20 \%$ p.a. through a triple screen strategy that combines momentum, term-structure and idiosyncratic volatility; Grundy and Martin (2001) generate $16.08 \%$ p.a. by adjusting momentum exposure to the market and size factors; Zhang (2006) generates $31.2 \%$ p.a. by trading stocks with momentum and high information uncertainty; Avramov et. al., (2007) also produce returns higher than 20\% p.a. by combining momentum with credit ratings; Balvers and Wu (2006) generate $19.4 \%$ p.a. by combining momentum with mean reversion.
} 
spectrum. ${ }^{23}$ The results in Table 5 present three important implications. First, while the single-sort momentum strategies produce statistically significant results and single-sort contrarian strategies do not, this suggests that contrarian strategies should not be used as a standalone single-sort strategy to allocate wealth in commodity futures. Second, the finding that the reversal signal can be employed to improve single-sort momentum strategies and the momentum signal can be used to improve single-sort contrarian strategies, confirm the hypothesis from Balvers and $\mathrm{Wu}$ (2006) and Serban (2010) that the momentum signal accelerates reversal and the reversal signal strengthens momentum. Last but not least, the fact that double-sort momentum-contrarian strategies outperform the contrarian-momentum strategies implies that the momentum effect is stronger than reversal in the commodity futures markets. As a result, we continue our detailed analysis of double-sort strategies with the momentum signal as the first-sort (i.e. Mom $12-\mathrm{Ctr}_{18}, \mathrm{Mom}_{12}-\mathrm{Ctr}_{24}$ and $\mathrm{Mom}_{12}-\mathrm{Ctr}_{36}$ ).

Figure 4 illustrates the superior performance of the double-sort over single-sort strategies and the passive long strategy. Both active strategies significantly outperform the passive longonly strategy. A \$1 investment in 1978 would be worth $\$ 2.40, \$ 113.78$ and $\$ 218.90$ at the end of the sample period by following the passive long, 12-1 momentum, and the double-sort 12-month momentum/24-month contrarian strategy, respectively. The single-sort and doublesort strategies both peaked at $\$ 154.20$ and $\$ 394.70$ in June 2008, only three months before the collapse of Lehman Brothers. Despite being extremely profitable, the double-sort strategy appears to be substantially more volatile compared to the single-sort strategy, indicating a

\footnotetext{
${ }^{23}$ Unlike in Fuertes et. al., (2010) and Fuertes et. al., (2015), where the second (third) sorts involve variables that are exogenous to past returns (i.e. term structure and idiosyncratic volatility), our proposed double-sort strategy exploits information only based on past returns. Consequently, in spite of a cautious selection, given the multitude of strategies as a result of different ranking and holding periods, a perfect comparison is close to impossible to achieve. To make meaningful and fair comparisons across all single-sort and double-sort strategies, we restrict the number of double-sort strategies to be identical. This results in 25 different combinations employed in both double-sort strategies (see Table 5 for details).
} 
higher level of risk that an investor needs to bear in order to capture these profits. Indeed, the return distribution illustrated in Figure 5 confirms this empirical observation.

Figure 5 illustrates the return distributions of the passive long, single-sort momentum strategy (Mom $12-1)$ and double-sort momentum/contrarian strategy (Mom $\left.12-\mathrm{Ctr}_{24}\right)$ for both S\&P and UBS datasets (The kernel used for smoothing the distribution is based on Epanechnikov, 1969). Clearly, both active strategies appear to be much riskier compared to the passive longonly strategy. On average, the annualized standard deviation of the double-sort strategies is 27.57\% compared to the $22.11 \%$ and $13.86 \%$ for Mom $_{12-1}$ and the passive long strategies, respectively (see Tables 2 and 4). Moreover, the 95\% VaR (based on normality) is $11.41 \%$, on average, for double-sort strategies, which is higher than $9.09 \%$ and $6.28 \%$ for Mom $_{12-1}$ and passive long, respectively. The Cornish-Fisher 99\% VaR of combined strategies increases substantially to $41.91 \%$ due to the large skewness and excess kurtosis, which is much higher than Mom $_{12-1}$ and the passive benchmark at $29.95 \%$ and $16.32 \%$, respectively. However, the higher risks borne in the combined strategies are well rewarded by the market. This is reflected in the Sharpe and Sortino ratios of the double-sort strategies which are superior to the Mom $_{12-1}$ and passive benchmark (0.74 and 1.59, on average, for double-sorted, 0.76 and 1.46 for single-sort, and 0.26 and 0.35 for passive long). On a risk-adjusted basis, Mom $_{12-}$ Ctr 18 remains the most successful investment strategy.

Although strategies with high returns are not uncommon in the momentum literature, we examine the performance of double-sort strategies in sub-periods as well as using the UBS data source to minimize the possibility of data mining. To save space, these results are not reported; however, the findings are consistent with the full-period results. Consistent with the full period results in Table 4, the double-sort strategies are profitable and significant in both sub-periods. The second-sort contrarian at the unconventional length (18 and 24 months) still 
outperforms the 36 and 48 month strategies. However, both the Sharpe and Sortino ratios show that the risk-adjusted return of double-sort strategies is indeed lower during the 19912011 period. The UBS data provides us with the opportunity to independently test and validate the performance of the double-sort strategies. Surprisingly, the profitability and significance of the double-sort strategies appear to be even stronger compared to the S\&Pbased results over the same period. Furthermore, the risk-adjusted performance is also superior. Based on the UBS data, the maximum drawdown and VaR are marginally lower compared to the test results using the S\&P data. The results confirm that the single-sort momentum strategy can be improved by incorporating reversal signals (using contrarian strategies).

Moreover, to check whether a particular sub-sector of commodities is driving the profitability of the double-sort strategies, Table 6 reports the performance of the three double-sort strategies when a particular sub-sector is excluded from the tests. The results show that the profitability of double-sort strategies remains strong and highly significant even when subsectors are excluded. Nonetheless, the Sharpe and Sortino ratios appear to be strongest when gold, silver and platinum are excluded. The VaR is the lowest when feeder cattle, lean hogs and live cattle are excluded from the sample. Notably, the short positions are greatly enhanced when energy or precious metals commodities are excluded from the sample. The overall results in Table 6 suggest that the combined strategy, which jointly exploits the momentum and reversal signal, is robust to commodity market seasonality or to minor changes in the market composition of the commodity futures universe.

\subsection{Factor loadings}

To better understand the dynamics of the double-sort strategies, we now turn our attention to risk factor exposures. It is important to examine whether systematic or macroeconomic risk 
factors may explain the variation of returns of these strategies. Table 7 reports the multifactor regression results of the double-sort strategies. Three strategies in total are selected for regression analysis. The first sort is the 12-month momentum signal and the second sort includes 18, 24 and 36-month reversal signals. Panel A shows the results of the Fuertes et. al., (2010) six-factor model, which consists of independent variables including returns on the S\&P500, S\&P GSCI, U.S. Government Bond, U.S. dollar effective exchange rate (FX) index, U.S. unexpected inflation (UI) and unexpected industrial production (UIP). While single-sort momentum strategies tend to load positively on commodity futures market returns (Table 3), the results in Panel A of Table 7 indicate that once combined with the reversal signal, the relationship ceases to hold.

Moreover, the double-sort strategies do not load significantly on any of the other factors, suggesting that the profitability of the combined strategy cannot be explained by U.S. stock and bond markets, currency or non-tradeable macroeconomic risks. As a result, the $R^{2}$ from these regressions are low and the unexplained excess returns remain large and significant for all strategies. Furthermore, Panel B reports the results of the Moskowitz et. al., (2012) sixfactor model, which includes independent variables such as the MSCI World Equity Index, S\&P GSCI, J.P. Morgan Global Government Bond Index, U.S. size, value and momentum factors. Although none of the factors appear to be significant, the intercepts become marginally lower from an average of $23.04 \%$ to $18.08 \%$ per year. ${ }^{24}$ These results suggest that the source of returns of the double-sort strategies cannot be explained by standard U.S. or global risk factors.

Recent research argues that the performance of long-short active investment strategies (including momentum) in commodity futures cannot be captured by conventional risk factors

\footnotetext{
${ }^{24}$ In addition to the JP Morgan Global Government Bond Index, we also used the Barclays Global Aggregate Bond to check the robustness of these results. We do not find inconsistent results despite the data of the latter being available from 1990.
} 
due to the passive and long-only nature of these risk factors (Erb and Harvey, 2006, Gorton et. al., 2013, Basu and Miffre, 2013). These studies have constructed a long-short based factor that captures the term structure premium and found that the slope of the term structure is an important risk factor that is unique in the commodity futures markets. Since all risk factors in Panels A and B assume long-only positions, it is important to examine whether the superior performance of double-sort strategies observed in this study can be explained by the dynamic, long-short based risk factor. Panel $\mathrm{C}$ reports the regression results of the Basu and Miffre (2013) term-structure premium. Again, the intercepts of these regressions remain large and statistically significant with low $R^{2}$ s. Clearly, these results suggest that the success of the double-sort strategies which jointly exploit momentum and reversal signals cannot be attributed to the dynamic, long-short term-structure factor that captures the fundamentals of backwardation and contango in commodity futures. ${ }^{25}$

To address the possibility of an omitted variable, Table 8 reports the factor loadings of the double-sort strategies on global funding liquidity, market volatility, investor sentiment and their extremes. We examine whether these variables can explain the double-sort strategy returns. Panel A shows the regression results of the TED spread, constructed by the difference between 3-month LIBOR and 3-month T-bill yield. Brunnermeier and Pedersen (2009), Moskowitz et. al., (2012) and Asness et. al., (2013) also use the TED spread as a proxy for global funding liquidity. Panel B shows the double-sort strategy's exposure to the VIX index, which is a proxy for market volatility. Panel C reports the loadings of the Baker

\footnotetext{
${ }^{25}$ To construct the slope of the term-structure factor, we follow Fuertes et. al., (2010) and Basu and Miffre (2013), and the results are reported in Table 7 based on terciles breakpoints. For robustness reasons, we also tested median breakpoints and found consistent results. The long-short based hedging pressure risk premium studied by Basu and Miffre (2013) cannot be examined in this paper due to data availability issues. As CFTC's commitment of traders (COT) data is only accessible from 1991, this only covers less than half of our sample period. However, this would constitute an interesting avenue for future research when more data becomes available.
} 
and Wurgler (2007) sentiment factors. ${ }^{26}$ To capture the top and/or bottom $20 \%$ most extreme realizations of the liquidity funding environment, market volatility and investor sentiment, we estimate quantile regressions. The first row of Panel A of Table 8 shows that there is no significant relationship between funding liquidity and the profitability of double-sort strategies. However, during the most extreme episodes of illiquidity, the double-sort strategies exhibit a significant positive relationship with the TED spread, implying that these strategies perform better during periods of extreme liquidity shocks. ${ }^{27}$ Strikingly, this relationship is not found when using a single-sort 12-month momentum strategy alone. The finding implies that combining momentum with a reversal/contrarian signal may improve our understanding of the dynamics of momentum. Panels B and C reveal no relationship between the double-sort strategies and market volatility, sentiment factors and their extremes. The relationship in Panel A of Table 8 is better visualized graphically.

Figure 6 illustrates the demeaned return of the Mom12-Ctr24 and the TED spread from 1986 to 2011. The top $25 \%$ of observations of the TED spread depicted by diamond plots indicates the most extreme realizations of global funding liquidity events, which reflect the 1987 stock market crash, 2001 dot-com bubble, September $11^{\text {th }}$ 2001, the 2007 quant meltdown and the collapse of Bear Stearns and Lehman Brothers in 2008. The double-sort strategy seems to perform better under these extreme liquidity funding environments. This finding has important implications for the funds management industry. Since most traditional investments (including long-only passive commodities funds) decline in value during extreme liquidity events (Asness et. al., 2013, Pastor and Stambaugh, 2003), the proposed dynamic double-sort strategy in commodity futures markets has the potential to reduce overall risk and

\footnotetext{
${ }^{26}$ Three-month T-bill and LIBOR rates are obtained from the Federal Reserve Bank of St. Louis. The data on the VIX is obtained from the Chicago Board Options Exchange (CBOE). Sentiment factors are downloaded from Jeffrey Wurgler's NYU website.

${ }^{27}$ For robustness reasons, we also use the U.S. aggregate liquidity factor (Pastor and Stambaugh, 2003). We did not find significant relationships based on either full or the extreme quantile of liquidity, and the loser portfolios are significant at the $10 \%$ level in some cases.
} 
improve the returns of traditional portfolios. Thus, this double-sort strategy can be employed as a viable portfolio diversification tool, providing much needed protection from these turbulent market conditions (refer to Table 10).

Furthermore, the double-sort (Mom-Ctr) strategy's links with funding liquidity presented in this study support the previous findings in Asness et. al., (2013). In their study, Asness et. al., (2013) show that momentum (value) is positively (negatively) related to liquidity risk only when these strategies are formed globally across asset classes. They use 12-month past returns as the momentum signal and a ratio of the past five-years to the most recent price as the value signal. Since this study focuses only on commodity futures, it is not surprising that the single-sort momentum does not exhibit a significant relationship with the TED-spread. Moreover, Asness et. al., (2013) also show that a global multi-asset class momentum and value combined strategy is related to a number of liquidity proxies. The value signal employed by Asness et. al., (2013) is similar to the second sort contrarian/reversal employed in this study. Thus, our results support the findings of Asness et. al., (2013), given that the double-sort strategy of commodity futures is also related to extreme periods of global funding liquidity.

\subsection{Decomposition of strategy returns}

Since the returns of the combined strategy are related to the most extreme realizations of global funding liquidity, we examine this relationship further. Table 9 reports the regression results of pure momentum/reversal and decomposed double-sort strategy returns during extreme liquidity conditions. The dependent variables are decomposed strategy returns and the independent variables are the TED spread and its extreme observations. In Panel A, although the contrarian strategy with a ranking period of 24 months is significant at the $10 \%$ level, a pure single-sort momentum or contrarian/reversal does not appear to be related to the 
TED spread or its extremes. The results suggest that the liquidity link is not purely due to momentum or contrarian/reversal. Interestingly, if neither momentum nor reversal is directly related to liquidity, then what is driving the link between extreme liquidity conditions and the double-sort strategy returns?

To understand these findings, we decompose the double-sort strategy return in Panel B, by introducing an interaction term between momentum and reversal. The following relationship is assumed:

$$
M O M_{J 1, t}-C T R_{J 2, t} \equiv M O M_{J-K, t}+C T R_{J-K, t}+I N T E R_{t}
$$

where $M O M_{J 1, t}-C T R_{J 2, t}$ denotes the double-sort strategy return, $M O M_{J-K, t}$ denotes the singlesort momentum strategy, $C T R_{J-K, t}$ denotes the single-sort reversal/contrarian return and $I N T E R_{t}$ represents the interaction term between the momentum and reversal strategies. The interaction term, which is not captured when examining momentum and reversal alone, is difficult to quantify. Following Elton et. al., (1993), an orthogonalization process is implemented to isolate the dynamics of this interaction term from the double-sort strategy returns. The following regression specifies the setup of the orthogonalization process:

$$
\operatorname{MOM}_{J 1, t}-C T R_{J 2, t}=\alpha_{i}+\beta_{M} M O M_{J-K, t}+\beta_{C} C T R_{J-K, t}+\epsilon_{t}
$$

where $\alpha_{i}$ is the intercept term, $\beta_{M}$ and $\beta_{C}$ are the coefficients of the momentum and contrarian/reversal components, respectively; and $\epsilon_{t}$ is the random error term. To eliminate the influence of momentum, we first estimate the above regression by setting $\beta_{C}=0$. Subsequently, MOM ${ }_{J 1, t}-C T R_{J 2, t}{ }^{\text {NON-Mom }}$ (orthogonal to momentum) is created by using the intercept plus the residuals as a new time series. Similarly, the influence of the 
contrarian/reversal returns can be eliminated by re-estimating Equation (2) with $\beta_{M}=0$. The interaction term can be isolated by estimating Equation (2) with no imposed restrictions.

Panel B of Table 9 reports the regression results on orthogonalized returns. MOMJ1,t$C T R_{J 2, t}{ }^{N O N-M o m}$ and $M O M_{J 1, t}-C T R_{J 2, t}{ }^{\text {NON-Ctr }}$ denotes the orthogonalized double-sort strategy with momentum or reversal returns removed, respectively. $M O M_{J 1, t}-C T R_{J 2, t}{ }^{N O N-M o m \& C t}$ denotes the orthogonalized double-sort strategy with both momentum and reversal returns eliminated. According to the assumptions in Equation (1), MOM ${ }_{J 1, t}-C T R_{J 2, t}{ }^{\text {NON-Mom\&Ctr }}$ is defined as the interaction term. First, when $M O M_{J 1, t}-C T R_{J 2, t}{ }^{N O N-M o m}$ is the dependent variable (momentum is removed with contrarian and interaction terms remaining), there is a weak relationship with extreme liquidity (significant at the $5 \%$ level). However, since the pure contrarian term in Panel A is not related to liquidity, the result may imply the significance of the interaction term. Second, when $M O M_{J 1, t}-C T R_{J 2, t}{ }^{N O N-C t r}$ is the dependent variable (the contrarian term is removed with momentum and interaction remaining), the link to extreme liquidity conditions appears to be strong. However, since pure momentum is not related to extreme liquidity, the significance of the coefficient hints again at the importance of the interaction term. Finally, when $M O M_{J 1, t}-C T R_{J 2, t}{ }^{N O N-M o m \& C r t}$ is the dependent variable (momentum and contrarian terms are both eliminated with the interaction term remaining), the link with extreme liquidity remains relatively strong. ${ }^{28}$ Overall, the findings in Table 9 suggest that the double-sort strategy exhibits a link with extreme liquidity conditions and the source of this relationship is the interaction between the momentum and reversal returns.

Asness et. al., (2013) show that when data are pooled across asset classes, momentum (value) tends to load positively (negatively) on liquidity. However, this relationship is not present within each asset class. Meanwhile, they also find that momentum and value are negatively

\footnotetext{
${ }^{28}$ Logit regressions confirm the findings in Table 9. In the interests of brevity, these results are not reported, but they are available upon request.
} 
correlated both within and across asset classes. They explain that the negative correlation could be driven by the behavior of pure momentum and contrarian investors during liquidity shocks. For example, both momentum and contrarian investors will engage in sell-offs when a liquidity shock occurs. These sell-offs by momentum traders will put more pressure on the price compared to contrarian traders due to the higher popularity (more crowded trades) and profitability of momentum strategies.

Consistent with Asness et. al., (2013), we find that momentum and contrarian strategies alone do not exhibit statistical significance with funding liquidity in commodity futures; however, when momentum is combined with reversal in a joint framework, this hidden relationship becomes apparent. Notably, the statistical significance is only present during the most extreme episodes of liquidity shocks (e.g. the 87' US stock market crash, the 97' Asian financial crisis, 00' internet bubble, 08' Lehman Brothers). Therefore, we conjecture that our decomposed interaction term may be capturing the negative correlation between momentum and contrarian. Thus, during extreme liquidity events, an investor who is neither pure momentum nor contrarian but blends momentum with contrarian, will likely achieve a better outcome because the interaction term of these two strategies provides more information about commodities that may be declining less (for long portfolios) or declining more (for short portfolios) than other commodities. This would not be possible if a single momentum or reversal signal is used.

\subsection{Data-snooping and transaction costs}

To examine whether the profitability of double-sort strategies is due to luck or random noise in the data, we perform further data-mining checks using the White (2000) Reality Check (RC) and Hansen (2005) Superior Predictive Ability (SPA) tests. The null hypothesis is that the average performance of the benchmark is as small as the minimum average performance 
across the strategies being tested. The alternative is that the minimum average loss across the strategies is smaller than the average performance of the benchmark. As a test of robustness, we consider three different bootstrap block lengths, namely 2, 10 and 20 months. At each length, both stationary and circular bootstraps are performed based on 10,000 replications. ${ }^{29}$ Pairwise comparisons with respect to the benchmark are not performed because the alternative strategies are ignored (as they suffer from data-mining problems). Appendix 1 reports the RC and SPA results. Panel A reports all strategies against the equal-weighted long-only benchmark. Panel B reports 13 single-sort strategies against the passive benchmark, and Panel C reports 12 double-sort strategies against the benchmark. Panel D reports 12 double-sort strategies against the most profitable single-sort active strategy as the benchmark. Overall, the results in Appendix 1 consistently suggest the rejection of the null hypothesis, therefore, confirming that the superiority of active single- and double-sort strategies is not due to data mining.

Although not explicitly accounted for in this study, the transaction costs of active strategies are unlikely to be a major issue. First, Lesmond et. al., (2004) estimate a transaction cost of 2.3\% per trade and Jegadeesh and Titman (1993) used a more conservative 0.5\% per trade in the equities market. However, as Locke and Venkatesh (1997) and Marshall et. al., (2012) show, transaction costs in the futures markets range from $0.0004 \%$ to $0.033 \%$ per trade. This is significantly lower than in equities markets. Second, short selling in the equities market is often subject to specific constraints. In some cases, the special requirements lead to increased trading costs. However, in extreme cases, there may be short-sell bans on stocks, which makes long-short active strategies (such as a momentum strategy) difficult to implement in a real market environment. In commodity futures; however, taking a short position is just as easy as taking a long position. Third, single or multi-sorted momentum strategies in the

\footnotetext{
${ }^{29}$ Kevin Sheppard's BSDS Matlab routine is gratefully acknowledged. The stationary and circular bootstrap is based on Politis and Romano (1994) and Politis and Romano (1992), respectively.
} 
equities market require the purchase and sale of a large number (hundreds) of stocks across the entire market (or a segment of the market). As noted by Korajczyk and Sadka (2004), this will undoubtedly put pressure on the net profits generated from momentum trades. However, within the commodity futures universe, around 50 commodities (excluding emissions and other exotic commodities) are currently being traded actively on exchanges across the globe; of these, the 27 most liquid markets are selected for the formation of momentum strategies in this study. Compared to the stock market, the cross-section of commodity futures markets drastically reduces the trading intensity necessary to implement single or double-sort momentum/contrarian strategies.

Despite the advantages described above, it is important to quantify the level of transaction costs specific to double-sort strategies presented in this study. We adopt the proxy for transaction cost estimates suggested in Fuertes et. al., (2010). Similar to the double-sort strategy in this study, Fuertes et. al., (2010) employ a double-sort strategy that combines momentum with a term structure signal. Based on their sample of 37 commodities, they estimated an annual portfolio turnover of 9.24 times, on average, across six double-sort strategies. ${ }^{30}$ Taking the highest turnover ratio (10.38 times) from Fuertes et. al., (2010), the transaction cost is a mere $0.69 \%$ per annum. Since Fuertes et. al., (2010) also use a 1-month holding period, quintile first-sort and median second-sort break point for portfolio formation, the transaction costs may be overstated in this case given that our sample includes fewer commodities. Clearly, the magnitude of profits presented in this study is far too large to be subsumed by the estimated transaction costs.

\subsection{Diversification benefits}

\footnotetext{
${ }^{30}$ The turnover ratio considered in this case includes the rolling over of futures contracts and changes in portfolio composition. Price impact, commissions and monthly rebalancing to equal weights are ignored.
} 
The proposed double-sort strategy can provide portfolio diversification benefits to GTAA teams at institutional funds (GTAA refers to Global Tactical Asset Allocation). Table 10 reports the Pearson correlations of the double-sort strategy returns with traditional asset classes. Panel A shows that the average correlation of the single-sort momentum strategies with GSCI and the U.S. cross-sectional UMD momentum factor is 0.21 and 0.15 , respectively (both significant at the 1\% level). The strategy correlations with the S\&P500, T-bond and FX index are close to zero and insignificant. On the contrary, Panel B shows that double-sort strategies exhibit no associations with the GSCI and UMD, which report an average correlation of 0.045 and 0.055 , respectively. In fact, the correlations are insignificant across the board.

Table 10 suggests that single-sort momentum strategies follow the general movements of commodity futures markets and U.S. equity momentum, but are unrelated to traditional asset classes such as equities and bonds. The double-sort strategies that jointly exploit momentum and reversal remain unrelated to traditional asset classes; however, they do not appear to be associated with commodities and equity momentum. A plausible explanation lies within the second sort of the double-sort strategy. Since the second sort takes a contrarian view of the market, the characteristics of momentum are neutralized by the opposite positions taken in the reversal signal. Therefore, the results imply that systematically allocating wealth towards high momentum commodities that are strengthened by reversal signals can assist in earning higher returns while reducing overall risk.

\subsection{Performance over an extended dataset}

In this section of the study, we assess the sensitivity of the results to the significant decline in commodities prices from January 2012 to December 2014. Table 11 reports the performance of the 12-month single-sort momentum strategy $\left(\mathrm{Mom}_{12-1}\right)$ and three double-sort strategies 
(Mom $12-\mathrm{Ctr}_{18}, \mathrm{Mom}_{12}-\mathrm{Ctr}_{24}$ and $\left.\mathrm{Mom}_{12}-\mathrm{Ctr}_{36}\right)$. Panels A and B report long and short portfolios, respectively. Panel C reports the long-short portfolios. While still remaining statistically significant, both the single-sort momentum and double-sort momentumcontrarian strategies exhibit marginal declines in profitability.

This marginal decrease in profitability appears to be smaller for double-sort strategies. For example, the 12-month single-sort momentum strategy report a return of $14.74 \%$ p.a. compared to the $16.88 \%$ p.a. (a decline of $2.14 \%$ p.a.) based on the original sample period. The average of the three double-sort momentum-contrarian strategies returned $21.57 \%$ p.a., which is only $0.65 \%$ p.a. lower than the average of $22.22 \%$ p.a. based on the original sample period. It is not surprising that both strategies report weaker profits given that the overall commodity markets experienced significant declines in the last three years from 2012-2014. However, during this market environment (when the S\&P GSCI lost more than $30 \%$ in value), Mom $_{12-1}$ and Mom $_{12}-\mathrm{Ctr}_{18}$ continue to report positive reward-to-risk ratios of 0.33 and 0.72 , respectively. These recent findings once again confirm that our main results are not samplespecific.

\section{Conclusion}

This study examines profitable trading strategies that jointly exploit momentum and reversal signals in commodity futures. The results suggest that buying winner commodities and short selling loser commodities in the past 12-months produces statistically significant profits. The profitability of a simple single-sort momentum strategy is strong and robust across subperiods and persistent in both S\&P and UBS data sets. Moreover, a detailed performance analysis reveals that momentum strategies are much riskier compared to the passive long- 
only benchmark. However, the increased riskiness leads to much improved Sharpe ratios over the benchmark return.

Furthermore, this study performs an extensive set of post-holding/formation analyzes on commodity momentum. The results find that regardless of the look-back period used, momentum profits in commodity futures peak at around 11 months after portfolio formation. Moreover, a consistent reversal pattern is pronounced at 2.5 years (30 months) even after controlling for commodity sector seasonality. The observed reversal pattern seems to be consistent with the overreaction hypothesis, leading to the conclusion that commodity market corrections for overreaction occur more rapidly compared to stock market corrections, which typically take 3 to 5 years. Furthermore, the persistent reversal pattern uncovered in this study implies that contrarian strategies formed at conventional look-back and holding periods are unsuccessful in commodity futures. Strikingly however, momentum profits tend to increase from 30 months and continue to persist beyond 60 months after portfolio formation. This is largely inconsistent with existing rational and behavioral attempts in explaining momentum. The rationale behind this unusual pattern is beyond the scope of this study, but it constitutes an interesting avenue for future research.

Using the insights obtained from the observed reversal pattern, we show that a double-sort strategy that jointly exploits momentum and reversal signals cross-sectionally produces economic and statistically significant returns. The novel double-sort strategy substantially outperforms the pure momentum strategies on a risk-adjusted basis. The fact that the performance improvement does not come from long or short positions alone, but both long and short portfolios, implies that under a joint framework, momentum accelerates reversal and reversal strengthens momentum. 
The profitability of the double-sort strategy is robust to sector seasonality, data-mining and is persistent across sub-periods and datasets. Moreover, the success of the proposed strategy cannot be attributed to standard risk factors, the commodity-specific dynamic risk factor (i.e. slope of the term structure), market volatility or investor sentiment. Furthermore, the profitability of double-sort strategies is too large to be overwhelmed by transaction costs. However, consistent with recent studies on value and momentum combined strategies (Asness et. al., 2013), we find that the returns of the double-sort strategy are at least partially related to global funding liquidity. Furthermore, the performance of double-sort strategies is unrelated to the dynamics of traditional asset classes, indicating that tactically allocating wealth towards high momentum commodities whose returns are strengthened by reversal signals can enhance the returns while reducing the risk of traditional investment portfolios (i.e. stocks and bonds). Finally, since the construction of the double-sort strategies requires nothing but past commodity prices, its apparent profitability poses significant challenges to the random walk hypothesis in the context of commodity futures.

\section{Acknowledgements}

The authors wish to thank Carol Alexander (the editor), two anonymous referees, Graham Bornholt, Stephen Brown, Adam Clements, Adrian Fernandez-Perez, Ana-Maria Fuertes, Bruce Grundy, Rakesh Gupta, Richard Heaney, Petko Kalev, Andrew Kaleel, Mathew Kaleel, Bin Li, Joelle Miffre, Paresh Narayan, Suman Neupane, Eduardo Roca, Raymond da Silva Rosa, Jeremy Schwartz, Daniel Smith, Neda Todorova, Bruce Vanstone, Adam Walk, Terry Walter, Kent Wang and Robert Webb for helpful comments. We also wish to thank seminar participants at Griffith University, Queensland University of Technology, University of Western Australia and Bond University. We acknowledge Standard and Poor's Sydney for their cooperation. Financial support from H3 Global Advisors, the Griffith Centre for 
Personal Finance and Superannuation (GCPFS) and Griffith University is gratefully acknowledged. All errors are our own

\section{References}

Ankrim, Ernest M, \& Hensel, Chris R. (1993). Commodities in asset allocation: a real-asset alternative to real estate? Financial Analysts Journal, 49(3), 20-29.

Anson, Mark JP. (1999). Maximizing utility with commodity futures diversification. The Journal of Portfolio Management, 25(4), 86-94.

Asness, Clifford S, Moskowitz, Tobias J, \& Pedersen, Lasse Heje. (2013). Value and momentum everywhere. The Journal of Finance, 68(3), 929-985.

Avramov, Doron, Chordia, Tarun, Jostova, Gergana, \& Philipov, Alexander. (2007). Momentum and credit rating. The Journal of Finance, 62(5), 2503-2520.

Baker, Malcolm, \& Wurgler, Jeffrey. (2007). Investor Sentiment in the Stock Market. Journal of Economic Perspectives, 21(2), 129-152.

Balvers, Ronald J, \& Wu, Yangru. (2006). Momentum and mean reversion across national equity markets. Journal of Empirical Finance, 13(1), 24-48.

Barberis, Nicholas, Shleifer, Andrei, \& Vishny, Robert. (1998). A model of investor sentiment. Journal of Financial Economics, 49(3), 307-343.

Basu, Devraj, \& Miffre, Joelle. (2013). Capturing the risk premium of commodity futures: The role of hedging pressure. Journal of Banking and Finance, 37(11), 2652-2664.

Bloomfield, Robert J, Tayler, William B, \& Zhou, Flora Hailan. (2009). Momentum, reversal, and uninformed traders in laboratory markets. The Journal of Finance, 64(6), 2535-2558.

Bodie, Zvi. (1983). Commodity futures as a hedge against inflation. The Journal of Portfolio Management, 9(3), 12-17.

Bodie, Zvi, \& Rosansky, Victor I. (1980). Risk and return in commodity futures. Financial 
Analysts Journal, 36(3), 27-39.

Boni, Leslie, \& Womack, Kent L. (2006). Analysts, industries, and price momentum. Journal of Financial and Quantitative Analysis, 41(01), 85-109.

Brunnermeier, Markus K, \& Pedersen, Lasse Heje. (2009). Market liquidity and funding liquidity. Review of Financial Studies, 22(6), 2201-2238.

Carchano, Óscar, \& Pardo, Ángel. (2009). Rolling over stock index futures contracts. Journal of Futures Markets, 29(7), 684-694.

Cargill, Thomas F, \& Rausser, Gordon C. (1975). Temporal price behavior in commodity futures markets. The Journal of Finance, 30(4), 1043-1053.

Chan, Louis KC, Jegadeesh, Narasimhan, \& Lakonishok, Josef. (1996). Momentum strategies. The Journal of Finance, 51(5), 1681-1713.

Chen, Long, Kadan, Ohad, \& Kose, Engin. (2009). Fresh Momentum. Olin School of Business. Washington University in St. Louis. St. Louis.

Cochrane, John H. (1999). New facts in finance (Vol. No.7169): National Bureau of Economic Research.

Conrad, Jennifer, \& Kaul, Gautam. (1998). An anatomy of trading strategies. Review of Financial Studies, 11(3), 489-519.

Cooper, Michael J, Gutierrez, Roberto C, \& Hameed, Allaudeen. (2004). Market states and momentum. The Journal of Finance, 59(3), 1345-1365.

DeBondt, Werner FM, \& Thaler, Richard H. (1985). Does the stock market overreact? The Journal of Finance, 40(3), 793-805.

DeBondt, Werner FM, \& Thaler, Richard H. (1987). Further evidence on investor overreaction and stock market seasonality. The Journal of Finance, 42(3), 557-581.

DowJones. (2012). The Dow Jones-UBS Commodity Index Handbook. DJ-UBSCI.

Elton, Edwin J, Gruber, Martin Jay, Das, Sanjiv, \& Hlavka, Matthew. (1993). Efficiency with costly information: A reinterpretation of evidence from managed portfolios. Review of 
Financial Studies, 6(1), 1-22.

Epanechnikov, Vassiliy A. (1969). Non-parametric estimation of a multivariate probability density. Theory of Probability \& Its Applications, 14(1), 153-158.

Erb, Claude B, \& Harvey, Campbell R. (2006). The strategic and tactical value of commodity futures. Financial Analysts Journal, 62(2), 69-97.

Fama, Eugene F. (1970). Efficient capital markets: a review of theory and emprical work. The Journal of Finance, 25(2), 383-417.

Fuertes, Ana-Maria, Miffre, Joëlle, \& Rallis, Georgios. (2010). Tactical allocation in commodity futures markets: Combining momentum and term structure signals. Journal of Banking \& Finance, 34(10), 2530-2548.

Fuertes, Ana-Maria, Miffre, Joëlle, \& Fernandez-Perez, Adrian (2015). Commodity strategies based on momentum, term structure and idiosyncratic volatility. Journal of Futures Markets, 35(3), 274-297.

Fung, William, \& Hsieh, David A. (2001). The risk in hedge fund strategies: Theory and evidence from trend followers. Review of Financial Studies, 14(2), 313-341.

Gorton, Gary, Hayashi, Fumio, \& Rouwenhorst, Geert. (2013). The fundamentals of commodity futures returns. Review of Finance, 17(1), 35-105.

Gorton, Gary, \& Rouwenhorst, K. Geert. (2006). Facts and Fantasies about Commodity Futures. Financial Analysts Journal, 62(2), 47-68.

Grundy, Bruce D, \& Martin, J Spencer. (2001). Understanding the nature of the risks and the source of the rewards to momentum investing. Review of Financial Studies, 14(1), 29-78.

Hansen, Peter Reinhard. (2005). A test for superior predictive ability. Journal of Business \& Economic Statistics, 23(4), 365-380.

Hunt, Lester C, Judge, Guy, \& Ninomiya, Yasushi. (2003). Underlying trends and seasonality in UK energy demand: a sectoral analysis. Energy Economics, 25(1), 93-118.

Jegadeesh, Narasimhan, \& Titman, Sheridan. (1993). Returns to buying winners and selling 
losers: Implications for stock market efficiency. The Journal of Finance, 48(1), 65-91.

Jegadeesh, Narasimhan, \& Titman, Sheridan. (2001). Profitability of momentum strategies: An evaluation of alternative explanations. The Journal of Finance, 56(2), 699-720.

Jensen, Gerald R, Johnson, Robert R, \& Mercer, Jeffrey M. (2000). Efficient use of commodity futures in diversified portfolios. Journal of Futures Markets, 20(5), 489-506.

Jensen, Gerald R, Johnson, Robert R, \& Mercer, Jeffrey M. (2002). Tactical asset allocation and commodity futures. The Journal of Portfolio Management, 28(4), 100-111.

Kenyon, David, Kling, Kenneth, Jordan, Jim, Seale, William, \& McCabe, Nancy. (1987). Factors affecting agricultural futures price variance. Journal of Futures Markets, 7(1), 73-91.

Korajczyk, Robert A, \& Sadka, Ronnie. (2004). Are momentum profits robust to trading costs? The Journal of Finance, 59(3), 1039-1082.

Lee, Charles, \& Swaminathan, Bhaskaran. (2000). Price momentum and trading volume. The Journal of Finance, 55(5), 2017-2069.

Lesmond, David A, Schill, Michael J, \& Zhou, Chunsheng. (2004). The illusory nature of momentum profits. Journal of Financial Economics, 71(2), 349-380.

Leuthold, Raymond M. (1972). Random walk and price trends: the live cattle futures market. The Journal of Finance, 27(4), 879-889.

Locke, Peter R, \& Venkatesh, PC. (1997). Futures market transaction costs. Journal of Futures Markets, 17(2), 229-245.

Ma, Christopher K, Mercer, Jeffrey M, \& Walker, Matthew A. (1992). Rolling over futures contracts: A note. Journal of Futures Markets, 12(2), 203-217.

Malin, Mirela, \& Bornholt, Graham. (2013). Long-term return reversal: Evidence from international market indices. Journal of International Financial Markets, Institutions and Money, 25, 1-17.

Marshall, Ben R, Cahan, Rochester H, \& Cahan, Jared M. (2008). Can commodity futures be profitably traded with quantitative market timing strategies? Journal of Banking \& 
Finance, 32(9), 1810-1819.

Marshall, Ben R, Nguyen, Nhut H, \& Visaltanachoti, Nuttawat. (2012). Commodity liquidity measurement and transaction costs. Review of Financial Studies, 25(2), 599-638.

Miffre, Joëlle, \& Rallis, Georgios. (2007). Momentum strategies in commodity futures markets. Journal of Banking \& Finance, 31(6), 1863-1886.

Milonas, Nikolaos T. (1991). Measuring seasonalities in commodity markets and the half-month effect. Journal of Futures Markets, 11(3), 331-345.

Moskowitz, Tobias J, \& Grinblatt, Mark. (1999). Do industries explain momentum? The Journal of Finance, 54(4), 1249-1290.

Moskowitz, Tobias J, Ooi, Yao Hua, \& Pedersen, Lasse Heje. (2012). Time series momentum. Journal of Financial Economics, 104(2), 228-250.

Newey, K. \& West, D. (1987). Hypothesis testing with efficient method of moments estimation. International Economic Review, 28, 777-787.

Novy-Marx, Robert. (2012). Is momentum really momentum? Journal of Financial Economics, 103(3), 429-453.

Pardo, Angel, Meneu, Vicente, \& Valor, Enric. (2002). Temperature and seasonality influences on Spanish electricity load. Energy Economics, 24(1), 55-70.

Pastor, Lubos, \& Stambaugh, Robert F. (2003). Liquidity risk and expected stock returns. The Journal of Political Economy, 111(3), 642-685.

Politis, Dimitris N, \& Romano, Joseph P. (1992). A circular block-resampling procedure for stationary data. In R. LePage \& L. Billard (Eds.), Exploring the limits of bootstrap (pp. 263-270).

Politis, Dimitris N, \& Romano, Joseph P. (1994). The stationary bootstrap. Journal of the American Statistical Association, 89(428), 1303-1313.

Roll, Richard. (1984). Orange juice and weather. The American Economic Review, 74(5), 861880. 
Rouwenhorst, K Geert. (1998). International momentum strategies. The Journal of Finance, 53(1), 267-284.

Sagi, Jacob S, \& Seasholes, Mark S. (2007). Firm-specific attributes and the cross-section of momentum. Journal of Financial Economics, 84(2), 389-434.

Serban, Alina F. (2010). Combining mean reversion and momentum trading strategies in foreign exchange markets. Journal of Banking \& Finance, 34(11), 2720-2727.

Shen, Qian, Szakmary, Andrew C, \& Sharma, Subhash C. (2007). An examination of momentum strategies in commodity futures markets. Journal of Futures Markets, 27(3), 227-256.

Spurgin, Richard B. (1999). A benchmark for commodity trading advisor performance. The Journal of Alternative Investments, 2(1), 11-21.

Standard \& Poor's. (2012). S\&P GSCI Methodology. S\&P Dow Jones Indices.

Stevenson, Richard A, \& Bear, Robert M. (1970). Commodity futures: trends or random walks? The Journal of Finance, 25(1), 65-81.

Wang, Changyun, \& Yu, Min. (2004). Trading activity and price reversals in futures markets. Journal of Banking \& Finance, 28(6), 1337-1361.

White, Halbert. (2000). A reality check for data snooping. Econometrica, 68(5), 1097-1126.

Yao, Yaqiong. (2012). Momentum, contrarian, and the January seasonality. Journal of Banking \& Finance, 36(10), 2757-2769.

You, Leyuan, \& Daigler, Robert T. (2010). Using four-moment tail risk to examine financial and commodity instrument diversification. Financial Review, 45(4), 1101-1123.

Zhang, X. (2006). Information uncertainty and stock returns. The Journal of Finance, 61(1), 105137. 
Table 1 Summary statistics

\begin{tabular}{|c|c|c|c|c|c|c|c|c|}
\hline Sector & Commodity & Ticker & Exchange & Start Date & Mean & Std. Dev. & Skew. & Kurt. \\
\hline \multicolumn{9}{|c|}{ Panel A: Standard and Poor's (Datastream) } \\
\hline \multirow{6}{*}{ Energy } & Brent & SPGSBRP & ICE & Jan-99 & 0.0199 & 0.1020 & -0.7439 & 4.6684 \\
\hline & Crude oil & SPGSCLP & NYMEX & Jan-87 & 0.0111 & 0.1013 & 0.0408 & 5.9941 \\
\hline & Gas oil & SPGSGOP & ICE & Jan-99 & 0.0188 & 0.0997 & -0.4519 & 4.0433 \\
\hline & Heating oil & SPGSHOP & NYMEX & Jan-83 & 0.0087 & 0.0947 & 0.3502 & 6.4801 \\
\hline & Natural gas & SPGSNGP & NYMEX & Jan-94 & -0.0155 & 0.1445 & 0.3612 & 3.1833 \\
\hline & RBOB gas & SPGSHUP & NYMEX & Jan-88 & 0.0159 & 0.1091 & 0.6835 & 9.4236 \\
\hline \multirow[t]{3}{*}{ Precious metals } & Gold & SPGSGCP & COMEX & Jan-78 & 0.0024 & 0.0552 & 1.2423 & 10.3330 \\
\hline & Platinum & SPGSPLP & NYMEX & Jan-84 & 0.0063 & 0.0659 & 0.1232 & 7.9249 \\
\hline & Silver & SPGSSIP & COMEX & Jan-77 & 0.0048 & 0.1027 & 1.2799 & 10.5395 \\
\hline \multirow[t]{3}{*}{ Live stock } & Feeder cattle & SPGSFCP & CME & Jan-02 & 0.0033 & 0.0431 & -0.1196 & 3.7510 \\
\hline & Lean hogs & SPGSLHP & CME & Jan-77 & 0.0084 & 0.0939 & 0.0721 & 5.3187 \\
\hline & Live cattle & SPGSLCP & CME & Jan-77 & 0.0035 & 0.0436 & -0.1634 & 4.6348 \\
\hline \multirow[t]{6}{*}{ Industrial metals } & Aluminum & SPGSIAP & LME & Jan-91 & -0.0015 & 0.0537 & -0.1526 & 4.2818 \\
\hline & Copper & SPGSICP & LME & Jan-77 & 0.0078 & 0.0779 & -0.0010 & 7.7151 \\
\hline & Lead & SPGSILP & LME & Jan-95 & -0.0006 & 0.0677 & 0.1626 & 4.3974 \\
\hline & Nickel & SPGSIKP & LME & Jan-93 & 0.0106 & 0.1042 & 0.0274 & 4.1040 \\
\hline & Tin & SPGCISP & LME & Mar-07 & 0.0171 & 0.1094 & -0.4762 & 3.6790 \\
\hline & Zinc & SPGSIZP & LME & Jan-91 & 0.0008 & 0.0733 & -0.1577 & 5.8946 \\
\hline \multirow[t]{9}{*}{ Agriculture } & Сосоа & SPGSCCP & ICE & Jan-84 & -0.0038 & 0.0814 & 0.4696 & 4.1137 \\
\hline & Coffee & SPGSKCP & ICE & Jan-81 & 0.0021 & 0.1070 & 1.6694 & 10.9384 \\
\hline & Corn & SPGSCNP & CBOT & Jan-77 & -0.0041 & 0.0699 & 1.0872 & 12.9898 \\
\hline & Cotton & SPGSCTP & ICE & Jan-77 & 0.0006 & 0.0704 & 0.4960 & 4.5392 \\
\hline & Soybean & SPGSSOP & СВОT & Jan-77 & 0.0087 & 0.0762 & -0.9434 & 7.2886 \\
\hline & Soybean oil & SPGSBOP & СBOT & Jan-05 & 0.0015 & 0.0664 & 0.3242 & 4.8548 \\
\hline & Sugar & SPGSSBP & ICE & Jan-77 & 0.0017 & 0.1082 & 0.6215 & 4.2342 \\
\hline & Wheat Chicago & SPGSWHP & CBOT & Jan-77 & -0.0011 & 0.0790 & 0.1435 & 3.9517 \\
\hline & Wheat Kansas & SPGSKWP & KCBT & Jan-99 & -0.0037 & 0.0711 & 0.6607 & 6.2202 \\
\hline \multicolumn{9}{|c|}{ Panel B: Dow Jones (Bloomberg) } \\
\hline \multirow[t]{6}{*}{ Energy } & Brent & DJUBSCO & ICE & Jan-91 & 0.0107 & 0.0823 & -0.1469 & 4.4944 \\
\hline & Crude oil & DJUBSCL & NYMEX & Jan-91 & 0.0075 & 0.0893 & -0.0167 & 3.8608 \\
\hline & Gas oil & DJUBSGO & ICE & Jan-91 & 0.0086 & 0.0849 & -0.0238 & 3.9658 \\
\hline & Heating oil & DJUBSHO & NYMEX & Jan-91 & 0.0069 & 0.0877 & 0.1497 & 3.9741 \\
\hline & Natural gas & DJUBSNG & NYMEX & Jan-91 & -0.0072 & 0.1396 & 0.5132 & 3.7548 \\
\hline & RBOB gas & DJUBSRB & NYMEX & Jan-91 & 0.0101 & 0.0931 & -0.0821 & 4.8486 \\
\hline \multirow[t]{3}{*}{ Precious metals } & Gold & DJUBSGC & COMEX & Jan-91 & 0.0040 & 0.0453 & 0.2284 & 4.5225 \\
\hline & Platinum & DJUBSPL & NYMEX & Jan-91 & 0.0075 & 0.0597 & -0.7215 & 7.0963 \\
\hline & Silver & DJUBSS & COMEX & Jan-91 & 0.0080 & 0.0840 & -0.0020 & 3.9158 \\
\hline \multirow[t]{2}{*}{ Live stock } & Lean hogs & DJUBSLH & CME & Jan-91 & -0.0068 & 0.0701 & -0.0883 & 3.6405 \\
\hline & Live cattle & DJUBSLC & CME & Jan-91 & -0.0008 & 0.0389 & -0.5891 & 5.5900 \\
\hline \multirow[t]{6}{*}{ Industrial metals } & Aluminum & DJUBSAL & LME & Jan-91 & -0.0018 & 0.0556 & 0.1135 & 3.4538 \\
\hline & Copper & DJUBSHG & COMEX & Jan-91 & 0.0082 & 0.0762 & -0.1177 & 5.7702 \\
\hline & Lead & DJUBSPB & LME & Jan-91 & 0.0060 & 0.0815 & -0.0015 & 4.2248 \\
\hline & Nickel & DJUBSNI & LME & Jan-91 & 0.0071 & 0.0991 & 0.2454 & 3.7151 \\
\hline & Tin & DJUBSSN & LME & Jan-91 & 0.0067 & 0.0669 & 0.5126 & 5.0019 \\
\hline & Zinc & DJUBSZS & LME & Jan-91 & 0.0012 & 0.0740 & -0.0387 & 4.9539 \\
\hline \multirow[t]{9}{*}{ Agriculture } & Сосоа & DJUBSCC & NYBOT & Jan-91 & -0.0015 & 0.0873 & 0.5930 & 4.1532 \\
\hline & Coffee & DJUBSKC & NYBOT & Jan-91 & 0.0008 & 0.1126 & 1.0509 & 5.5401 \\
\hline & Corn & DJUBSCN & СBOT & Jan-91 & -0.0040 & 0.0744 & -0.0509 & 3.4027 \\
\hline & Cotton & DJUBSCT & NYBOT & Jan-91 & -0.0029 & 0.0798 & 0.3301 & 3.6428 \\
\hline & Soybean & DJUBSSY & CBOT & Jan-91 & 0.0054 & 0.0692 & -0.1681 & 3.7567 \\
\hline & Soybean oil & DJUBSBO & СВОТ & Jan-91 & 0.0013 & 0.0724 & 0.0980 & 4.7605 \\
\hline & Soybean meal & DJUBSSM & CBOT & Jan-91 & 0.0094 & 0.0732 & 0.1904 & 3.8025 \\
\hline & Sugar & DJUBSSB & NYBOT & Jan-91 & 0.0073 & 0.0922 & 0.1523 & 3.4733 \\
\hline & Wheat & DJUBSWH & CBOT & Jan-91 & -0.0038 & 0.0796 & 0.3797 & 4.9218 \\
\hline
\end{tabular}

This table lists all commodity futures included in the sample sorted by sector information. For each commodity, Table 1 summarizes its ticker symbol, futures exchange and inception dates. Summary statistics (monthly mean, standard deviation, skewness and kurtosis) of the raw returns are also reported. Panel A reports the Standard and Poor's data obtained from Datastream International and Panel B summarizes the Dow Jones data obtained from Bloomberg. 
Table 2 Performance of single-sort momentum strategies

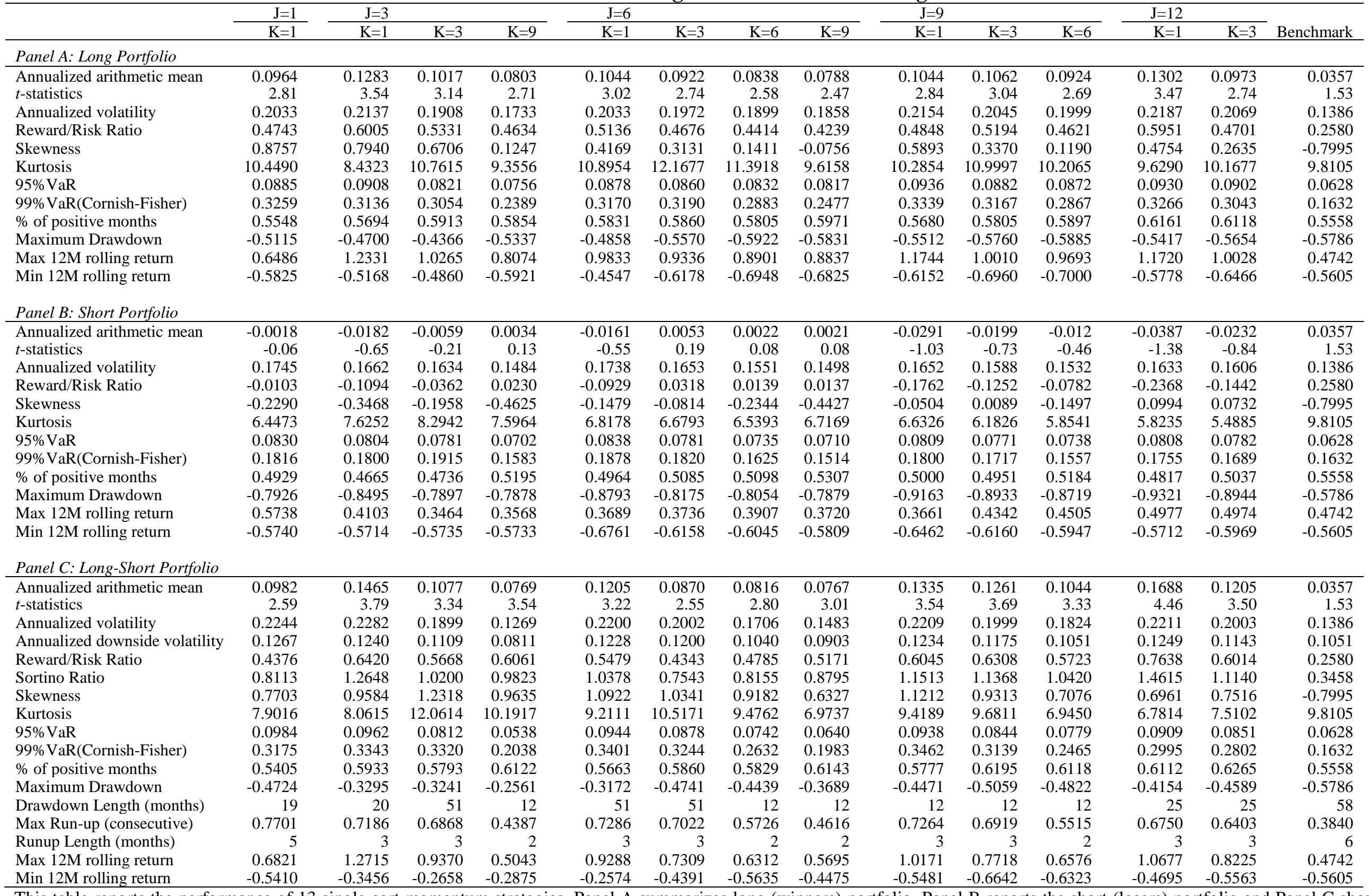

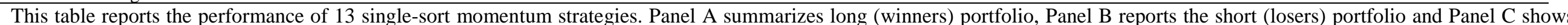
the long-short (winners-losers) portfolio. $J$ and $K$ represent ranking and holding periods. Sortino is benchmarked at $0 \%$. Reward/risk is equivalent to the Sharpe ratio in this case. 
Table 3 Performance of single-sort contrarian strategies

\begin{tabular}{|c|c|c|c|c|c|c|c|c|c|c|c|c|c|c|c|c|}
\hline \multirow{3}{*}{$\begin{array}{l}\text { Ranking } \\
\text { Periods }\end{array}$} & \multicolumn{16}{|c|}{ Holding Periods } \\
\hline & & \multicolumn{3}{|c|}{$K=18$} & \multicolumn{3}{|c|}{$K=24$} & \multicolumn{3}{|c|}{$K=30$} & \multicolumn{3}{|c|}{$K=48$} & \multicolumn{3}{|c|}{$K=60$} \\
\hline & & Winners & Losers & $\mathrm{L}-\mathrm{W}$ & Winners & Losers & $\mathrm{L}-\mathrm{W}$ & Winners & Losers & $\mathrm{L}-\mathrm{W}$ & Winners & Losers & $\mathrm{L}-\mathrm{W}$ & Winners & Losers & $\mathrm{L}-\mathrm{W}$ \\
\hline \multirow[t]{2}{*}{$J=15$} & Return (р.a.) & 0.0119 & 0.0242 & 0.0123 & 0.0105 & 0.0132 & 0.0027 & 0.0111 & 0.0011 & -0.0100 & 0.0405 & 0.0133 & -0.0272 & 0.0425 & 0.0149 & -0.0276 \\
\hline & $t$-statistics & 0.36 & 0.91 & 0.43 & 0.34 & 0.50 & 0.11 & 0.38 & 0.04 & -0.45 & 1.41 & 0.51 & -1.40 & 1.45 & 0.57 & -1.47 \\
\hline \multirow[t]{2}{*}{$J=18$} & Return (р.а.) & 0.0026 & 0.0169 & 0.0143 & 0.0072 & 0.0087 & 0.0014 & 0.0145 & 0.0004 & -0.0140 & 0.0441 & 0.0149 & -0.0292 & 0.0404 & 0.0099 & -0.0305 \\
\hline & $t$-statistics & 0.08 & 0.64 & 0.49 & 0.23 & 0.33 & 0.06 & 0.49 & 0.02 & -0.62 & 1.51 & 0.58 & -1.43 & 1.36 & 0.38 & -1.55 \\
\hline \multirow[t]{2}{*}{$J=24$} & Return (р.a.) & 0.0132 & 0.0100 & -0.0031 & 0.0156 & 0.0001 & -0.0155 & 0.0343 & 0.0020 & -0.0323 & 0.0448 & 0.0117 & -0.033 & 0.0477 & 0.0099 & -0.0378 \\
\hline & $t$-statistics & 0.40 & 0.38 & -0.10 & 0.51 & 0.00 & -0.57 & 1.14 & 0.07 & -1.26 & 1.49 & 0.44 & -1.42 & 1.54 & 0.37 & -1.66 \\
\hline \multirow[t]{2}{*}{$J=30$} & Return (р.а.) & 0.0125 & -0.0013 & -0.0138 & 0.0315 & -0.0007 & -0.0322 & 0.0443 & 0.0046 & -0.0397 & 0.0459 & 0.0044 & -0.0415 & 0.0541 & 0.0109 & -0.0433 \\
\hline & $t$-statistics & 0.39 & -0.05 & -0.45 & 1.01 & -0.02 & -1.11 & 1.43 & 0.17 & -1.41 & 1.47 & 0.16 & -1.60 & 1.69 & 0.39 & -1.70 \\
\hline \multirow[t]{2}{*}{$J=36$} & Return (р.a.) & 0.0311 & -0.0082 & -0.0393 & 0.0436 & -0.0007 & -0.0443 & 0.0593 & 0.0005 & -0.0587 & 0.0528 & 0.0020 & -0.0508 & 0.0606 & 0.0154 & -0.0451 \\
\hline & $t$-statistics & 0.99 & -0.30 & -1.29 & 1.40 & -0.02 & -1.48 & 1.92 & 0.02 & -2.01 & 1.67 & 0.07 & -1.83 & 1.88 & 0.55 & -1.65 \\
\hline \multirow[t]{2}{*}{$J=48$} & Return (р.а.) & 0.0555 & 0.0023 & -0.0532 & 0.0497 & 0.0083 & -0.0414 & 0.0554 & -0.0026 & -0.0579 & 0.065 & 0.0143 & -0.0507 & 0.0697 & 0.0156 & -0.0541 \\
\hline & $t$-statistics & 1.72 & 0.08 & -1.58 & 1.53 & 0.29 & -1.26 & 1.70 & -0.09 & -1.78 & 1.90 & 0.49 & -1.56 & 1.98 & 0.53 & -1.68 \\
\hline \multirow[t]{2}{*}{$J=60$} & Return (р.а.) & 0.0434 & 0.0082 & -0.0352 & 0.0512 & 0.0035 & -0.0477 & 0.0578 & 0.0033 & -0.0545 & 0.0728 & 0.0142 & -0.0586 & 0.068 & 0.0164 & -0.0516 \\
\hline & $t$-statistics & 1.29 & 0.28 & -1.03 & 1.52 & 0.12 & -1.41 & 1.70 & 0.11 & -1.62 & 2.05 & 0.49 & -1.74 & 1.87 & 0.56 & -1.55 \\
\hline
\end{tabular}

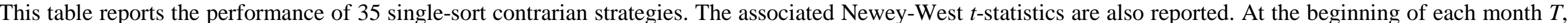

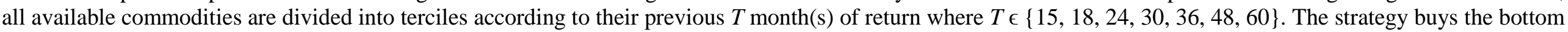

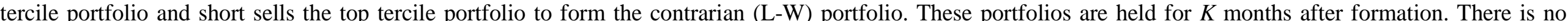

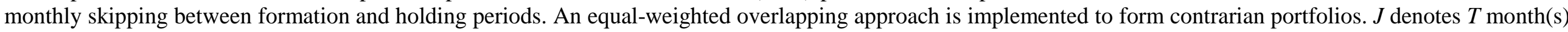
of portfolio formation periods. $K$ denotes the portfolio holding periods. 
Table 4 Performance of double-sort strategies

\begin{tabular}{|c|c|c|c|c|c|c|c|c|c|}
\hline & $\begin{array}{l}\text { Momi2- }_{12-} \\
\text { Ctr }_{18} \\
\end{array}$ & $\begin{array}{l}\text { Momi2- }_{12-} \\
\text { Ctr }_{24}\end{array}$ & $\begin{array}{l}\text { Momi2- }_{12-} \\
\text { Ctrr36 }^{-1}\end{array}$ & $\begin{array}{l}\text { Momi2- }_{12-} \\
\text { Ctr }_{48}\end{array}$ & $\begin{array}{l}\text { Ctr } 18^{-} \\
\text {Mom }_{12} \\
\end{array}$ & $\begin{array}{l}\text { Ctr24- } \\
\text { Mom }_{12} \\
\end{array}$ & $\begin{array}{l}\mathrm{Ctr}_{36^{-}} \\
\mathrm{Mom}_{12} \\
\end{array}$ & $\begin{array}{l}\text { Ctr }_{48-} \\
\text { Mom }_{12} \\
\end{array}$ & Mom $_{12-1}$ \\
\hline \multicolumn{10}{|l|}{ Panel A: Long Portfolio } \\
\hline Annualized arithmetic & 0.1824 & 0.1648 & 0.1316 & 0.0858 & 0.1066 & 0.1158 & 0.0685 & 0.1276 & 0.1302 \\
\hline Annualized volatility & 0.2351 & 0.2717 & 0.2632 & 0.2364 & 0.3201 & 0.3341 & 0.2789 & 0.2543 & 0.2187 \\
\hline Reward/Risk Ratio & 0.7756 & 0.6065 & 0.5001 & 0.3629 & 0.333 & 0.3892 & 0.2456 & 0.5019 & 0.5951 \\
\hline Sortino Ratio & 1.4596 & 1.1642 & 0.8985 & 0.6269 & 0.2914 & 0.4265 & 0.0823 & 0.5081 & 0.9666 \\
\hline \multicolumn{10}{|l|}{ Panel B: Short Portfolio } \\
\hline Annualized arithmetic & -0.0825 & -0.0390 & -0.0663 & -0.0571 & -0.0338 & -0.0189 & -0.0225 & -0.0397 & -0.0387 \\
\hline t-statistics & -2.67 & -1.16 & -1.91 & -1.62 & -0.95 & -0.55 & -0.65 & -1.10 & -1.38 \\
\hline Annualized volatility & 0.1793 & 0.1929 & 0.1963 & 0.196 & 0.2093 & 0.2 & 0.1994 & 0.2055 & 0.1633 \\
\hline Reward/Risk Ratio & -0.4599 & -0.2022 & -0.3376 & -0.2914 & -0.1615 & -0.0945 & -0.1127 & -0.193 & -0.2368 \\
\hline Sortino Ratio & -0.6536 & -0.2943 & -0.4704 & -0.3944 & -0.6839 & -0.6123 & -0.6425 & -0.7358 & -0.3595 \\
\hline$t$-statistics & 5.96 & 3.99 & 3.89 & 3.02 & 2.27 & 2.32 & 1.60 & 3.06 & 4.46 \\
\hline Annualized geometric & 0.2334 & 0.164 & 0.1591 & 0.1097 & 0.0816 & 0.0873 & 0.0398 & 0.126 & 0.1452 \\
\hline Annualized volatility & 0.2576 & 0.2934 & 0.2883 & 0.2636 & 0.3478 & 0.3512 & 0.3152 & 0.2935 & 0.2211 \\
\hline Downside volatility & 0.1336 & 0.1471 & 0.1452 & 0.136 & 0.18 & 0.1789 & 0.1829 & 0.1522 & 0.1249 \\
\hline Reward/Risk Ratio & 1.0281 & 0.6945 & 0.6863 & 0.5421 & 0.4166 & 0.4315 & 0.2947 & 0.5913 & 0.7638 \\
\hline Sortino Ratio & 2.2412 & 1.5221 & 1.4931 & 1.1221 & 0.4807 & 0.5191 & 0.2022 & 0.7483 & 1.4615 \\
\hline Skewness & 0.8424 & 1.5539 & 1.3594 & 0.9054 & 1.184 & 1.3053 & 0.1474 & 0.6189 & 0.6961 \\
\hline Kurtosis & 5.8276 & 11.5537 & 9.7229 & 7.0243 & 10.6549 & 10.8192 & 7.3984 & 8.0757 & 6.7814 \\
\hline Max monthly gain & 0.4079 & 0.6161 & 0.5543 & 0.4921 & 0.6125 & 0.6012 & 0.5444 & 0.5855 & 0.397 \\
\hline Max monthly loss & -0.2046 & -0.244 & -0.2046 & -0.1868 & -0.3838 & -0.3838 & -0.4023 & -0.2824 & -0.178 \\
\hline 95\%VaR & 0.1003 & 0.1223 & 0.1204 & 0.1133 & 0.1485 & 0.1351 & 0.1353 & 0.1435 & 0.0909 \\
\hline 99\%VaR(Cornish-Fisher) & 0.3435 & 0.5065 & 0.4624 & 0.3641 & 0.569 & 0.5805 & 0.39 & 0.4143 & 0.2995 \\
\hline$\%$ of positive months & 0.6253 & 0.597 & 0.6182 & 0.6247 & 0.5955 & 0.6196 & 0.639 & 0.7024 & 0.6112 \\
\hline Maximum Drawdown & -0.3898 & -0.5177 & -0.5435 & -0.5468 & -0.7619 & -1.0887 & -2.1354 & -0.7147 & -0.4154 \\
\hline
\end{tabular}

This table reports the performance of the double-sort strategies. Mom $_{J 1}-\mathrm{Ctr}_{J 2}$ represents strategies with the momentum signal as the first sort and the reversal signal as the second sort, where $J 1=12$ months and $J 2=18,24,36$ and 48 months. $C_{t r} r_{J 1}-M_{0 m}{ }_{J 2}$ represents double-sort strategies with reversal signal as the first sort and the momentum signal as the second sort, where $J 1=18$, 24, 36 and 48 months and $J 2=12$ months. Panels A and B summarize the long and short portfolios, respectively, whereas Panel $\mathrm{C}$ reports the long-short portfolio. These double-sort strategies are benchmarked against the single-sort 12-month momentum strategy. The sample period covers the period 1977 to 2011 and includes 27 S\&P commodity futures. 
Table 5 Performance summary of single and double-sort strategies

\begin{tabular}{|c|c|c|c|c|c|c|c|c|c|c|c|c|}
\hline & \multicolumn{3}{|c|}{ Single-sort Momentum } & \multicolumn{3}{|c|}{ Single-sort Contrarian } & \multicolumn{3}{|c|}{ Double-sort Momentum-Contrarian } & \multicolumn{3}{|c|}{ Double-sort Contrarian-Momentum } \\
\hline & Best & Worst & Mean & Best & Worst & Mean & Best & Worst & Mean & Best & Worst & Mean \\
\hline & Mom12-1 & Mom12-12 & & Ctr18-18 & Ctr48-36 & & Mom12-Ctr18 $_{18}$ & Mom1-Ctr18 & & Ctr $48-M_{12}$ & Ctr36-Mom9 & \\
\hline \multicolumn{13}{|l|}{ Panel A: Long Portfolio } \\
\hline Annualized arithmetic mean & 0.1302 & 0.0420 & 0.0830 & 0.0026 & 0.0600 & 0.0445 & 0.1824 & 0.1028 & 0.1124 & 0.1276 & 0.0255 & 0.0819 \\
\hline$t$-statistics & 3.47 & 1.23 & 2.53 & 0.08 & 1.81 & 1.38 & 4.49 & 2.72 & 2.82 & 2.65 & 0.46 & 1.62 \\
\hline Annualized volatility & 0.2187 & 0.1976 & 0.1910 & 0.1868 & 0.1756 & 0.1722 & 0.2351 & 0.2189 & 0.2287 & 0.2543 & 0.3139 & 0.2772 \\
\hline Reward/Risk Ratio & 0.5951 & 0.2127 & 0.4321 & 0.0140 & 0.3419 & 0.2585 & 0.7756 & 0.4695 & 0.4886 & 0.5019 & 0.0811 & 0.2977 \\
\hline Sortino Ratio & 0.9666 & 0.3055 & 0.6608 & 0.0199 & 0.4355 & 0.3397 & 1.4596 & 0.8070 & 0.8821 & 0.5081 & -0.1498 & 0.1769 \\
\hline Skewness & 0.4754 & 0.0552 & 0.1928 & 0.0382 & -1.1991 & -0.8485 & 1.0306 & 0.5810 & 0.8542 & 0.5544 & 1.0851 & 0.6302 \\
\hline Kurtosis & 9.6290 & 9.3214 & 9.9464 & 9.5329 & 12.4743 & 10.9493 & 9.4508 & 7.1632 & 9.2357 & 9.5421 & 14.5706 & 10.5870 \\
\hline \multicolumn{13}{|l|}{ Panel B: Short Portfolio } \\
\hline Annualized arithmetic mean & -0.0387 & 0.0185 & -0.0004 & 0.0169 & -0.0017 & 0.0062 & -0.0825 & 0.0119 & -0.0231 & -0.0397 & 0.0080 & -0.0308 \\
\hline t-statistics & -1.38 & 0.71 & 0.01 & 0.64 & -0.06 & 0.23 & -2.67 & 0.30 & -0.70 & -1.10 & 0.23 & -0.91 \\
\hline Annualized volatility & 0.1633 & 0.1505 & 0.1552 & 0.1488 & 0.1544 & 0.1489 & 0.1793 & 0.2275 & 0.2053 & 0.2055 & 0.2015 & 0.1950 \\
\hline Reward/Risk Ratio & -0.2368 & 0.1226 & 0.0016 & 0.1134 & -0.0111 & 0.0423 & -0.4599 & 0.0523 & -0.1220 & -0.1930 & 0.0396 & -0.1591 \\
\hline Sortino Ratio & -0.3595 & 0.1803 & -0.0007 & 0.1677 & -0.0165 & 0.0623 & -0.6536 & 0.0742 & -0.1747 & -0.7358 & -0.3856 & -0.7037 \\
\hline Skewness & 0.0994 & -0.3844 & -0.2937 & -0.3992 & -0.0349 & -0.2013 & 0.0357 & 0.0232 & -0.0933 & 0.2652 & 0.2971 & 0.3051 \\
\hline Kurtosis & 5.8235 & 5.5137 & 6.8584 & 5.8763 & 5.6237 & 6.1880 & 5.4279 & 7.5312 & 7.4561 & 4.1797 & 4.1068 & 4.7705 \\
\hline \multicolumn{13}{|l|}{ Panel C: Long-Short Portfolio } \\
\hline Annualized arithmetic mean & 0.1688 & 0.0236 & 0.0834 & 0.0143 & -0.0617 & 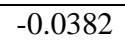 & 0.2648 & 0.0909 & 0.1355 & 0.1736 & 0.0174 & 0.1163 \\
\hline$t$-statistics & 4.46 & 0.78 & 2.88 & 0.49 & -1.91 & -1.33 & 5.96 & 1.89 & 2.95 & 3.06 & 0.30 & 2.02 \\
\hline Annualized geometric mean & 0.1452 & 0.0087 & 0.0688 & 0.0005 & -0.0763 & -0.0502 & 0.2334 & 0.0522 & 0.1008 & 0.1260 & -0.0371 & 0.0657 \\
\hline Annualized volatility & 0.2211 & 0.1740 & 0.1681 & 0.1652 & 0.1716 & 0.1541 & 0.2576 & 0.2788 & 0.2667 & 0.2935 & 0.3352 & 0.3091 \\
\hline Annualized downside volatility & 0.1249 & 0.1044 & 0.0988 & 0.1080 & 0.0992 & 0.0948 & 0.1336 & 0.1713 & 0.1535 & 0.1522 & 0.1927 & 0.1665 \\
\hline Reward/Risk Ratio & 0.7638 & 0.1354 & 0.4920 & 0.0863 & -0.3598 & -0.2484 & 1.0281 & 0.3259 & 0.5119 & 0.5913 & 0.0518 & 0.3786 \\
\hline Sortino Ratio & 1.4615 & 0.2283 & 0.8716 & 0.1329 & -0.6052 & -0.4003 & 2.2412 & 0.5532 & 0.9844 & 0.7483 & -0.1817 & 0.3627 \\
\hline Skewness & 0.6961 & 0.5031 & 0.8340 & -0.1396 & 0.5058 & 0.2692 & 0.8424 & 0.2686 & 0.6550 & 0.6189 & 0.8222 & 0.5949 \\
\hline Kurtosis & 6.7814 & 5.0811 & 8.3966 & 5.2799 & 4.0546 & 4.3479 & 5.8276 & 6.6261 & 6.9202 & 8.0757 & 9.4885 & 7.5551 \\
\hline $95 \% \mathrm{VaR}$ & 0.0909 & 0.0807 & 0.0729 & 0.0772 & 0.0866 & 0.0763 & 0.1003 & 0.1248 & 0.1153 & 0.1435 & 0.1300 & 0.1403 \\
\hline 99\%VaR(Cornish-Fisher) & 0.2995 & 0.2007 & 0.2439 & 0.1642 & 0.1791 & 0.1563 & 0.3435 & 0.3404 & 0.3534 & 0.4143 & 0.5016 & 0.4151 \\
\hline$\%$ of positive months & 0.6112 & 0.5754 & 0.5893 & 0.6010 & 0.6716 & 0.6639 & 0.6253 & 0.5459 & 0.5689 & 0.7024 & 0.5768 & 0.6448 \\
\hline Maximum Drawdown & -0.4154 & -0.5238 & -0.3669 & -0.6798 & -0.8898 & -0.8020 & -0.3898 & -0.4916 & -0.5083 & -0.7147 & -0.8286 & -0.8067 \\
\hline Drawdown Length (months) & 25 & 23 & 25 & 115 & 332 & 308 & 39 & 5 & 45 & 84 & 136 & 104 \\
\hline Max Run-up (consecutive) & 0.6750 & 0.3635 & 0.5277 & 0.3633 & 0.0000 & 0.1068 & 0.8935 & 0.5925 & 0.8314 & 0.5855 & 0.5825 & 0.7006 \\
\hline Runup Length (months) & 3 & 2 & 3 & 4 & 0 & 2 & 5 & 4 & 5 & 7 & 4 & 6 \\
\hline Max $12 \mathrm{M}$ rolling return & 1.0677 & 0.5152 & 0.6778 & 0.5960 & 0.3971 & 0.3680 & 1.5182 & 0.9375 & 1.1163 & 1.2789 & 1.2205 & 1.6020 \\
\hline Min $12 \mathrm{M}$ rolling return & -0.4695 & -0.4713 & -0.3919 & -0.4801 & -0.6064 & -0.5036 & -0.3609 & -0.3690 & -0.4497 & -0.4093 & -0.7708 & -0.5620 \\
\hline
\end{tabular}

This table reports the best, worst and average performance of single-sort momentum, single-sort contrarian, double-sort momentum-contrarian, and doublesort contrarian-momentum strategies. We employ 25 different ranking and holding period combinations across the four strategies totaling 100 strategies. For single-sort momentum, the ranking and holding periods are $T_{m}$ months, where $T_{m}=1,3,6,9$ and 12 . For single-sort contrarian, the ranking and holding periods are $T_{c}$ months, where $T_{c}=18,24,30,36$ and 48 months. For double-sort momentum-contrarian, the first sort ranking periods are $T_{m}$ months. Five second-sort ranking periods are 15, 18, 21, 24 and 30 months. For double-sort contrarian-momentum, the first sort ranking periods are $T_{c}$ months and second-sort ranking periods are $T_{m}$ months. For both double-sort strategies, the holding period is one month. Panels A and B summarize the long and short portfolios, respectively, whereas Panel C reports the long-short portfolio. The sample covers the period 1977 to 2011 and includes 27 S\&P commodity futures. 
Table 6 Performance of double-sort momentum strategies excluding sub-sectors

\begin{tabular}{|c|c|c|c|c|c|c|c|c|c|c|c|c|c|c|c|}
\hline & \multicolumn{3}{|c|}{ All excl. Agriculture } & \multicolumn{3}{|c|}{ All excl. Energy } & \multicolumn{3}{|c|}{ All excl. Industrial metals } & \multicolumn{3}{|c|}{ All excl. Livestock } & \multicolumn{3}{|c|}{ All excl. Precious metals } \\
\hline & $\begin{array}{l}\text { Mom }_{12-} \\
\text { Ctr }_{18} \\
\end{array}$ & $\begin{array}{l}\text { Momi2- }_{12} \\
\text { Ctr }_{24} \\
\end{array}$ & $\begin{array}{l}\text { Momi2- }_{12-} \\
\text { Ctr }_{36} \\
\end{array}$ & $\begin{array}{l}\text { Momi2- }_{12} \\
\text { Ctr }_{18} \\
\end{array}$ & $\begin{array}{l}\text { Mom }_{12-} \\
\text { Ctr }_{24} \\
\end{array}$ & $\begin{array}{l}\text { Momi2- }_{12-} \\
\text { Ctr }_{36} \\
\end{array}$ & $\begin{array}{l}\text { Momi2- }_{12} \\
\text { Ctr }_{18} \\
\end{array}$ & $\begin{array}{l}\text { Momi2- }_{12} \\
\text { Ctr }_{24} \\
\end{array}$ & $\begin{array}{l}\text { Momi2- } \\
\text { Ctr }_{36} \\
\end{array}$ & $\begin{array}{l}\text { Momi2- }_{12} \\
\text { Ctr }_{18} \\
\end{array}$ & $\begin{array}{l}\text { Momi2- } \\
\text { Ctr }_{24} \\
\end{array}$ & $\begin{array}{l}\text { Momi2- } \\
\mathrm{Ctr}_{36} \\
\end{array}$ & $\begin{array}{l}\text { Momi2- }_{12} \\
\text { Ctr }_{18} \\
\end{array}$ & $\begin{array}{l}\text { Mom12- } \\
\mathrm{Ctr}_{24} \\
\end{array}$ & $\begin{array}{l}\text { Momi2- }_{12} \\
\text { Ctr }_{36}\end{array}$ \\
\hline \multicolumn{16}{|l|}{ Panel A: Long Portfolio } \\
\hline Annualized arithmetic & 0.1721 & 0.1445 & 0.0970 & 0.1250 & 0.1193 & 0.0800 & 0.1541 & 0.1722 & 0.1010 & 0.1398 & 0.1603 & 0.1249 & 0.1560 & 0.1530 & 0.1137 \\
\hline$t$-statistics & 3.21 & 2.58 & 1.97 & 3.18 & 2.85 & 1.97 & 3.44 & 3.16 & 1.94 & 3.58 & 3.64 & 2.67 & 3.71 & 3.27 & 2.42 \\
\hline Annualized volatility & 0.3104 & 0.3223 & 0.2753 & 0.2281 & 0.2405 & 0.2296 & 0.2598 & 0.3133 & 0.2945 & 0.2265 & 0.2535 & 0.2650 & 0.2438 & 0.2691 & 0.2656 \\
\hline Reward/Risk Ratio & 0.5545 & 0.4483 & 0.3524 & 0.5481 & 0.4960 & 0.3483 & 0.5932 & 0.5498 & 0.3429 & 0.6172 & 0.6322 & 0.4713 & 0.6399 & 0.5686 & 0.4280 \\
\hline Sortino Ratio & 0.9148 & 0.7415 & 0.4743 & 1.0557 & 0.9750 & 0.6171 & 1.0965 & 1.1695 & 0.5355 & 0.9977 & 1.1052 & 0.8293 & 1.1255 & 0.9997 & 0.7209 \\
\hline Skewness & 1.2727 & 1.1527 & -0.5072 & 1.2395 & 2.1171 & 1.3416 & 1.5101 & 2.2098 & 0.6350 & 0.0417 & 0.6690 & 0.9747 & 0.8580 & 1.7306 & 1.1790 \\
\hline Kurtosis & 14.384 & 12.700 & 8.8113 & 9.7514 & 18.963 & 13.112 & 15.115 & 15.699 & 11.329 & 6.6635 & 11.002 & 11.548 & 9.8625 & 18.131 & 13.775 \\
\hline \multicolumn{16}{|l|}{ Panel B: Short Portfolio } \\
\hline Annualized arithmetic & -0.0267 & -0.0247 & -0.0280 & -0.0812 & -0.0435 & -0.0804 & -0.0739 & -0.0594 & -0.0776 & -0.0541 & -0.0229 & -0.0670 & -0.0904 & -0.0578 & -0.0790 \\
\hline$t$-statistics & -0.69 & -0.60 & -0.64 & -2.82 & -1.37 & -2.41 & -2.01 & -1.53 & -1.94 & -1.56 & -0.60 & -1.67 & -2.71 & -1.59 & -2.20 \\
\hline Annualized volatility & 0.2240 & 0.2350 & 0.2476 & 0.1668 & 0.1829 & 0.1888 & 0.2131 & 0.2235 & 0.2260 & 0.2010 & 0.2213 & 0.2276 & 0.1934 & 0.2091 & 0.2037 \\
\hline Reward/Risk Ratio & -0.1194 & -0.1049 & -0.1133 & -0.4870 & -0.2378 & -0.4260 & -0.3470 & -0.2659 & -0.3433 & -0.2690 & -0.1036 & -0.2943 & -0.4672 & -0.2763 & -0.3876 \\
\hline Sortino Ratio & -0.1757 & -0.1542 & -0.1648 & -0.6957 & -0.3573 & -0.6139 & -0.4602 & -0.3504 & -0.4606 & -0.3886 & -0.1500 & -0.4058 & -0.6724 & -0.4088 & -0.5604 \\
\hline Skewness & -0.0788 & -0.0041 & -0.0010 & -0.3180 & -0.1667 & -0.3625 & -0.3678 & -0.5020 & -0.4468 & 0.0908 & -0.0851 & -0.2025 & -0.0436 & -0.0064 & -0.0723 \\
\hline Kurtosis & 5.3535 & 5.2421 & 5.8563 & 6.1703 & 5.3984 & 6.5213 & 6.3078 & 6.9567 & 5.9599 & 6.2546 & 6.7826 & 6.1192 & 4.3140 & 4.1441 & 3.9700 \\
\hline \multicolumn{16}{|c|}{ Panel C: Long-Short Portfolio } \\
\hline Annualized arithmetic & 0.2046 & 0.1747 & 0.1206 & 0.2062 & 0.1628 & 0.1604 & 0.2280 & 0.2317 & 0.1786 & 0.1938 & 0.1832 & 0.1919 & 0.2464 & 0.2108 & 0.1926 \\
\hline$t$-statistics & 3.34 & 2.69 & 2.00 & 4.93 & 3.54 & 3.52 & 4.67 & 3.96 & 3.32 & 4.22 & 3.65 & 3.53 & 5.43 & 4.09 & 3.69 \\
\hline Annualized geometric & 0.1458 & 0.1094 & 0.0636 & 0.1784 & 0.1303 & 0.1290 & 0.1898 & 0.1795 & 0.1334 & 0.1591 & 0.1432 & 0.1468 & 0.2135 & 0.1697 & 0.1515 \\
\hline Annualized volatility & 0.3539 & 0.3716 & 0.3364 & 0.2422 & 0.2648 & 0.2583 & 0.2828 & 0.3366 & 0.3043 & 0.2663 & 0.2891 & 0.3080 & 0.2631 & 0.2964 & 0.2960 \\
\hline Downside volatility & 0.2030 & 0.2198 & 0.2270 & 0.1212 & 0.1271 & 0.1333 & 0.1752 & 0.1839 & 0.1924 & 0.1510 & 0.1518 & 0.1597 & 0.1349 & 0.1559 & 0.1515 \\
\hline Reward/Risk Ratio & 0.5780 & 0.4701 & 0.3584 & 0.8513 & 0.6147 & 0.6210 & 0.8065 & 0.6883 & 0.5869 & 0.7279 & 0.6338 & 0.6229 & 0.9364 & 0.7112 & 0.6509 \\
\hline Sortino Ratio & 1.1080 & 0.8618 & 0.5616 & 1.8719 & 1.3806 & 1.2961 & 1.4462 & 1.4025 & 1.0080 & 1.4040 & 1.3133 & 1.3126 & 2.0481 & 1.4911 & 1.3901 \\
\hline Skewness & 1.2751 & 1.1415 & 0.1240 & 0.9794 & 1.7259 & 1.3241 & 0.9255 & 1.4859 & 0.5177 & 0.2472 & 0.7387 & 0.8620 & 0.7965 & 1.3022 & 1.1547 \\
\hline Kurtosis & 10.878 & 10.008 & 6.3524 & 6.8338 & 13.337 & 10.574 & 10.777 & 10.577 & 6.8930 & 3.7762 & 5.8908 & 5.7309 & 5.8417 & 10.589 & 8.4210 \\
\hline Max monthly gain & 0.6287 & 0.6287 & 0.5290 & 0.4079 & 0.6161 & 0.5543 & 0.6231 & 0.6231 & 0.4620 & 0.2595 & 0.4860 & 0.4860 & 0.4148 & 0.6092 & 0.5293 \\
\hline Max monthly loss & -0.4090 & -0.4090 & -0.4090 & -0.2046 & -0.2046 & -0.2046 & -0.2611 & -0.2611 & -0.3538 & -0.2241 & -0.2440 & -0.2132 & -0.2046 & -0.2440 & -0.2093 \\
\hline 95\%VaR & 0.1510 & 0.1619 & 0.1497 & 0.0978 & 0.1122 & 0.1093 & 0.1153 & 0.1405 & 0.1296 & 0.1103 & 0.1220 & 0.1303 & 0.1044 & 0.1232 & 0.1245 \\
\hline 99\%VaR(Cornish-Fisher) & 0.5913 & 0.5934 & 0.3925 & 0.3395 & 0.4850 & 0.4275 & 0.4690 & 0.5592 & 0.4005 & 0.2814 & 0.3731 & 0.3990 & 0.3475 & 0.4929 & 0.4456 \\
\hline$\%$ of positive months & 0.6050 & 0.5964 & 0.6390 & 0.5980 & 0.5869 & 0.6156 & 0.6476 & 0.6247 & 0.6234 & 0.6005 & 0.5718 & 0.5948 & 0.6129 & 0.5995 & 0.6078 \\
\hline Maximum Drawdown & -0.6403 & -0.6273 & -0.6586 & -0.4119 & -0.5384 & -0.4211 & -0.4956 & -0.4771 & -0.4815 & -0.6128 & -0.6520 & -0.7180 & -0.3620 & -0.4631 & -0.6188 \\
\hline Drawdown Length & 6 & 4 & 24 & 32 & 38 & 38 & 38 & 22 & 3 & 32 & 33 & 43 & 17 & 28 & 44 \\
\hline Max Run-up (consecutive) & 1.1428 & 1.1428 & 0.3657 & 0.8935 & 1.1778 & 0.7314 & 1.0962 & 0.9277 & 0.5037 & 0.4905 & 0.4659 & 0.5729 & 0.9710 & 0.6100 & 0.6960 \\
\hline Runup Length (months) & 2 & 2 & 3 & 5 & 6 & 2 & 18 & 2 & 2 & 5 & 5 & 5 & 13 & 2 & 2 \\
\hline Max $12 \mathrm{M}$ rolling return & 1.0480 & 1.1711 & 0.9481 & 1.5182 & 1.5074 & 0.9420 & 1.1602 & 2.1388 & 0.7390 & 0.8777 & 0.7500 & 1.2485 & 1.3157 & 1.1772 & 1.0165 \\
\hline Min $12 \mathrm{M}$ rolling return & -0.7530 & -0.7086 & -0.7902 & -0.3941 & -0.4649 & -0.3588 & -0.2317 & -0.4211 & -0.3991 & -0.5619 & -0.6106 & -0.8105 & -0.3106 & -0.4258 & -0.5731 \\
\hline
\end{tabular}

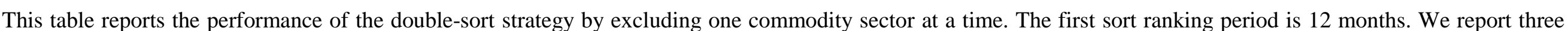

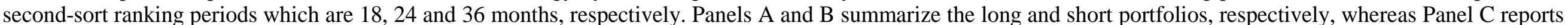

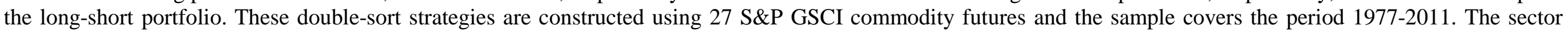
definitions are based on the S\&P index methodology. 
Table 7 Factor loadings of double-sort momentum-contrarian strategies

\begin{tabular}{|c|c|c|c|}
\hline & $\begin{array}{l}\text { Mom }_{12^{-}} \\
\text {Ctr }_{18}\end{array}$ & $\begin{array}{l}\mathrm{Mom}_{12-} \\
\mathrm{Ctr}_{24}\end{array}$ & $\begin{array}{l}\text { Mom }_{12^{-}} \\
\operatorname{Ctr}_{36}\end{array}$ \\
\hline \multicolumn{4}{|c|}{ Panel A: Fuertes, Miffre and Rallis (2010) Factors } \\
\hline S\&P500 & $\begin{array}{l}-0.0689 \\
(-0.75)\end{array}$ & $\begin{array}{l}0.0104 \\
(0.11)\end{array}$ & $\begin{array}{l}-0.0091 \\
(-0.12)\end{array}$ \\
\hline S\&P GSCI & $\begin{array}{l}0.113 \\
(0.94)\end{array}$ & $\begin{array}{l}0.160 \\
(1.12)\end{array}$ & $\begin{array}{l}0.0553 \\
(0.50)\end{array}$ \\
\hline US Govt Bond & $\begin{array}{l}0.278 \\
(1.28)\end{array}$ & $\begin{array}{l}0.457 \\
(1.62)\end{array}$ & $\begin{array}{l}0.325 \\
(1.03)\end{array}$ \\
\hline FX & $\begin{array}{l}-0.141 \\
(-0.55)\end{array}$ & $\begin{array}{l}-0.0583 \\
(-0.21)\end{array}$ & $\begin{array}{l}-0.0628 \\
(-0.24)\end{array}$ \\
\hline UI & $\begin{array}{l}-2.543 \\
(-2.31)\end{array}$ & $\begin{array}{l}-2.147 \\
(-1.67)\end{array}$ & $\begin{array}{l}-0.636 \\
(-0.43)\end{array}$ \\
\hline UIP & $\begin{array}{l}-0.605 \\
(-1.37)\end{array}$ & $\begin{array}{l}-0.467 \\
(-0.93)\end{array}$ & $\begin{array}{l}-0.976 \\
(-1.35)\end{array}$ \\
\hline Intercept & $\begin{array}{l}0.0220^{*} \\
(5.90)\end{array}$ & $\begin{array}{l}0.0172 * \\
(4.46)\end{array}$ & $\begin{array}{l}0.0184^{*} \\
(4.04)\end{array}$ \\
\hline adj. R-sq & 0.011 & 0.012 & -0.003 \\
\hline \multicolumn{4}{|c|}{ Panel B: Moskowitz, Ooi and Pedersen (2012) Factors } \\
\hline MSCI World & $\begin{array}{l}0.0131 \\
(0.15)\end{array}$ & $\begin{array}{l}0.0451 \\
(0.41)\end{array}$ & $\begin{array}{l}-0.0155 \\
(-0.16)\end{array}$ \\
\hline S\&P GSCI & $\begin{array}{l}-0.0802 \\
(-1.27)\end{array}$ & $\begin{array}{l}-0.0606 \\
(-0.97)\end{array}$ & $\begin{array}{l}-0.0310 \\
(-0.52)\end{array}$ \\
\hline Global Govt Bond & $\begin{array}{l}0.432 \\
(2.15)\end{array}$ & $\begin{array}{l}0.526 \\
(2.51)\end{array}$ & $\begin{array}{l}0.284 \\
(1.34)\end{array}$ \\
\hline SMB & $\begin{array}{l}0.202 \\
(1.22)\end{array}$ & $\begin{array}{l}0.143 \\
(1.01)\end{array}$ & $\begin{array}{l}0.114 \\
(0.83)\end{array}$ \\
\hline HML & $\begin{array}{l}0.202 \\
(1.60)\end{array}$ & $\begin{array}{l}0.176 \\
(1.15)\end{array}$ & $\begin{array}{l}0.0522 \\
(0.30)\end{array}$ \\
\hline UMD & $\begin{array}{l}0.0796 \\
(1.05)\end{array}$ & $\begin{array}{l}0.105 \\
(1.40)\end{array}$ & $\begin{array}{l}0.0804 \\
(0.82)\end{array}$ \\
\hline Intercept & $\begin{array}{l}0.0194^{*} \\
(5.39)\end{array}$ & $\begin{array}{l}0.0121 * \\
(3.29)\end{array}$ & $\begin{array}{l}0.0137 * \\
(3.07)\end{array}$ \\
\hline adj. R-sq & 0.012 & 0.013 & -0.008 \\
\hline \multicolumn{4}{|c|}{ Panel C: Basu and Miffre (2013) long-short term structure } \\
\hline Term-structure & $\begin{array}{l}0.0931 \\
(0.66)\end{array}$ & $\begin{array}{l}0.138 \\
(0.91)\end{array}$ & $\begin{array}{l}0.144 \\
(0.83)\end{array}$ \\
\hline Intercept & $\begin{array}{l}0.0215^{*} \\
(4.80)\end{array}$ & $\begin{array}{l}0.0162 * \\
(3.30)\end{array}$ & $\begin{array}{l}0.0157^{*} \\
(3.31)\end{array}$ \\
\hline R-sq & 0.001 & 0.004 & 0.005 \\
\hline
\end{tabular}

This table reports the factor loadings of double-sort strategies on standard asset pricing factors. The first sort ranking period is 12 months. The three second-sort ranking periods are 18, 24 and 36 months, respectively. The dependent variables are the double-sort strategy returns and the independent variables are the risk factors. Panel A summarizes the regression result of the Fuertes, Miffre and Rallis (2010) factors, Panel B reports the Moskowitz, Oio and Pedersen (2012) factors and Panel C summarizes the slope of the term structure factor in Basu and Miffre (2013). U.S. Govt Bond represents the Datastream U.S. Government Bond Index. FX denotes the U.S. dollar effective exchange rate index. UI and UIP represent unexpected inflation and unexpected industrial production, respectively. MSCI World represents the Morgan Stanley Capital International Global Equity Index. Global Govt Bond is proxied by the JP Morgan Global Government Bond Index. SMB, HML and UMD are the U.S. cross-sectional size, value and momentum factors, respectively, from the Kenneth French website. Since bond returns are not available from the start of the sample period, Panel A is the period 1980 to 2011 whereas Panel B is the period 1986 to 2011. Panel C is the period 1978 to 2011. The $t$-statistics are reported in brackets. * denotes statistical significance at the $5 \%$ level or better. Newey and West (1987) standard errors are employed. 
Table 8 Liquidity, volatility, sentiment and extremes

\begin{tabular}{|c|c|c|c|c|c|c|c|c|c|}
\hline & \multicolumn{3}{|c|}{$\mathrm{Mom}_{12}-\mathrm{Ctr}_{18}$} & \multicolumn{3}{|c|}{$\mathrm{Mom}_{12}-\mathrm{Ctr}_{24}$} & \multicolumn{3}{|c|}{$\mathrm{Mom}_{12}-\mathrm{Ctr}_{36}$} \\
\hline & $\alpha$ & $\beta$ & $R^{2}$ & $\alpha$ & $\beta$ & $R^{2}$ & $\alpha$ & $\beta$ & $R^{2}$ \\
\hline \multicolumn{10}{|c|}{ Panel A: TED Spread and Extremes } \\
\hline TED Spread & $\begin{array}{l}0.0183^{*} \\
(2.46)\end{array}$ & $\begin{array}{l}0.525 \\
(0.48)\end{array}$ & -0.002 & $\begin{array}{l}0.0108 \\
(1.33)\end{array}$ & $\begin{array}{l}0.492 \\
0.64)\end{array}$ & -0.002 & $\begin{array}{l}0.0126 \\
(2.16)\end{array}$ & $\begin{array}{l}0.379 \\
(0.49)\end{array}$ & -0.003 \\
\hline TED Spread Top 20\% & $\begin{array}{l}0.0381 * \\
(4.25)\end{array}$ & $\begin{array}{l}5.625^{*} \\
(4.41)\end{array}$ & & $\begin{array}{l}0.0503^{*} \\
(4.81)\end{array}$ & $\begin{array}{c}3.591^{*} \\
(2.2)\end{array}$ & & $\begin{array}{l}0.0472 * \\
(3.61)\end{array}$ & $\begin{array}{l}3.041^{*} \\
(2.47)\end{array}$ & \\
\hline \multicolumn{10}{|c|}{ Panel B: Market Volatility and Extremes } \\
\hline VIX & $\begin{array}{l}0.0217 * \\
(5.37)\end{array}$ & $\begin{array}{l}-0.0102 \\
(-0.76)\end{array}$ & -0.002 & $\begin{array}{l}0.0149 * \\
(3.51)\end{array}$ & $\begin{array}{l}-0.021 \\
(-1.04)\end{array}$ & 0.000 & $\begin{array}{l}0.0155^{*} \\
(3.83)\end{array}$ & $\begin{array}{l}-0.0153 \\
(-0.81)\end{array}$ & -0.001 \\
\hline VIX Top 20\% & $\begin{array}{l}0.0760^{*} \\
(9.58)\end{array}$ & $\begin{array}{l}-0.0304 \\
(-0.87)\end{array}$ & & $\begin{array}{l}0.0680^{*} \\
(10.48)\end{array}$ & $\begin{array}{c}-0.0383 \\
(-1.15)\end{array}$ & & $\begin{array}{l}0.0678^{*} \\
(8.88)\end{array}$ & $\begin{array}{l}-0.0242 \\
(-0.67)\end{array}$ & \\
\hline \multicolumn{10}{|c|}{ Panel C: Baker and Wurgler (2007) Sentiment Factors and Extremes } \\
\hline Sentiment & $\begin{array}{l}0.0235^{*} \\
(5.07)\end{array}$ & $\begin{array}{l}-0.0025 \\
(-0.49)\end{array}$ & -0.002 & $\begin{array}{l}0.0180 * \\
(3.36)\end{array}$ & $\begin{array}{c}-0.0017 \\
(-0.27)\end{array}$ & -0.002 & $\begin{array}{l}0.0169 * \\
(3.45)\end{array}$ & $\begin{array}{l}0.00142 \\
(0.25)\end{array}$ & -0.003 \\
\hline Sentiment Top 20\% & $\begin{array}{l}0.0778 * \\
(10.67)\end{array}$ & $\begin{array}{l}-0.0134 \\
(-1.33)\end{array}$ & & $\begin{array}{l}0.0746^{*} \\
(11.00)\end{array}$ & $\begin{array}{c}-0.0089 \\
(-0.93)\end{array}$ & & $\begin{array}{l}0.0703^{*} \\
(7.82)\end{array}$ & $\begin{array}{l}0.00274 \\
(0.22)\end{array}$ & \\
\hline Sentiment Bottom 20\% & $\begin{array}{l}-0.0336 * \\
(-6.47)\end{array}$ & $\begin{array}{l}0.0093 \\
(1.29)\end{array}$ & & $\begin{array}{l}-0.0432 * \\
(-7.40)\end{array}$ & $\begin{array}{l}0.0046 \\
(0.56)\end{array}$ & & $\begin{array}{l}-0.0442 * \\
(-7.69)\end{array}$ & $\begin{array}{l}0.0108 \\
(1.34)\end{array}$ & \\
\hline Change in Sentiment & $\begin{array}{l}0.0228^{*} \\
(5.57)\end{array}$ & $\begin{array}{l}-0.0005 \\
(-0.13)\end{array}$ & -0.003 & $\begin{array}{l}0.0175^{*} \\
(3.98)\end{array}$ & $\begin{array}{l}0.0013 \\
(0.37)\end{array}$ & -0.002 & $\begin{array}{l}0.0173^{*} \\
(3.94)\end{array}$ & $\begin{array}{l}-0.00215 \\
(-0.49)\end{array}$ & -0.002 \\
\hline $\begin{array}{l}\text { Change in sentiment } \\
\text { Top } 20 \%\end{array}$ & $\begin{array}{l}0.0723 * \\
(10.85)\end{array}$ & $\begin{array}{l}0.0056 \\
(0.85)\end{array}$ & & $\begin{array}{l}0.0714^{*} \\
(12.53)\end{array}$ & $\begin{array}{l}0.0027 \\
(0.48)\end{array}$ & & $\begin{array}{l}0.0724^{*} \\
(8.95)\end{array}$ & $\begin{array}{l}0.00149 \\
(0.19)\end{array}$ & \\
\hline $\begin{array}{l}\text { Change in Sentiment } \\
\text { Bottom } 20 \%\end{array}$ & $\begin{array}{l}-0.0290 * \\
(-6.75)\end{array}$ & $\begin{array}{l}-0.0075 \\
(-1.75) \\
\end{array}$ & & $\begin{array}{l}-0.0436 * \\
(-8.65) \\
\end{array}$ & $\begin{array}{c}-0.0061 \\
(-1.21) \\
\end{array}$ & & $\begin{array}{l}-0.0417 * \\
(-8.95)\end{array}$ & $\begin{array}{l}-0.00214 \\
(-0.46)\end{array}$ & \\
\hline
\end{tabular}

This table reports the factor loadings of the double-sort strategies on global funding liquidity, market volatility, investor sentiment factors and their extremes. The momentum sorting period is 12 months and the contrarian sorting periods are 18, 24 and 36 months, respectively. The dependent variables are the double-sort strategy returns and the independent variables are the risk factors and extremes. Panel A summarizes the regression results on the TED spread, Panel B reports market volatility exposure and Panel C summarizes the regression results on sentiment factors. TED spread is the difference between the yield on the 3-month LIBOR and T-bill. VIX denotes the Chicago Board Options Exchange (CBOE) Market Volatility Index. Baker and Wurgler (2007) sentiment factors are obtained from the Jeffrey Wurgler NYU website. Quantile regressions are estimated for all extreme estimations. The sample period is 1977 to 2011 . The $t$-statistics are reported in brackets. * denotes statistical significance at the $5 \%$ level or better. 
Table 9 Extreme funding liquidity and decomposed double-sort strategy return

\begin{tabular}{|c|c|c|c|c|c|c|c|c|c|}
\hline & $\alpha$ & $\beta$ & $R^{2}$ & $\alpha$ & $\beta$ & $R^{2}$ & $\alpha$ & $B$ & $R^{2}$ \\
\hline$M O M_{I-K}$ as dependent variable & & Mom $_{12-}$ & & & & & & & \\
\hline TED Spread & $\begin{array}{l}0.0134^{*} \\
(2.17)\end{array}$ & $\begin{array}{l}-0.085 \\
(-0.10)\end{array}$ & -0.003 & & & & & & \\
\hline TED Spread Top 20\% & $\begin{array}{l}0.0541^{*} \\
(6.68)\end{array}$ & $\begin{array}{l}0.547 \\
(0.54)\end{array}$ & & & & & & & \\
\hline$C T R_{I-K}$ as dependent variable & & $\mathrm{Ctr}_{18-1}$ & & & $\mathrm{Ctr}_{24-1}$ & & & $\mathrm{Ctr}_{36-1}$ & \\
\hline TED Spread & $\begin{array}{l}-0.0102 \\
(-1.74)\end{array}$ & $\begin{array}{l}0.794 \\
(0.97)\end{array}$ & 0.001 & $\begin{array}{l}-0.0164 * \\
(-3.01)\end{array}$ & $\begin{array}{l}1.764 * \\
(2.40)\end{array}$ & 0.016 & $\begin{array}{l}-0.0107 \\
(-1.89)\end{array}$ & $\begin{array}{l}0.783 \\
(1.01)\end{array}$ & 0.001 \\
\hline TED Spread Top 20\% & $\begin{array}{l}0.0348 * \\
(3.70)\end{array}$ & $\begin{array}{l}1.096 \\
(0.88)\end{array}$ & & $\begin{array}{l}0.0274^{*} \\
(3.11)\end{array}$ & $\begin{array}{l}2.316^{*} \\
(1.97)\end{array}$ & & $\begin{array}{l}0.0303^{*} \\
(4.59)\end{array}$ & $\begin{array}{l}1.495 \\
(1.83)\end{array}$ & \\
\hline \multicolumn{10}{|c|}{ Panel B: Orthogonalized double-sort return } \\
\hline$M O M_{I 1}-C T R_{I 2}{ }^{N O N-M o m}$ as dependent & \multicolumn{3}{|c|}{$\mathrm{Mom}_{12}-\mathrm{Ctr}_{18}$} & \multicolumn{3}{|c|}{ Mom $_{12}-\mathrm{Ctr}_{24}$} & $\alpha$ & Mom $_{12}-\mathrm{Ctr}_{36}$ & $R^{2}$ \\
\hline TED Spread & $\begin{array}{l}0.0069 \\
(1.49)\end{array}$ & $\begin{array}{l}0.598 \\
(0.89)\end{array}$ & -0.000 & $\begin{array}{l}-0.0019 \\
(-0.44)\end{array}$ & $\begin{array}{l}0.573 \\
(0.86)\end{array}$ & -0.000 & $\begin{array}{l}0.0003 \\
(0.06)\end{array}$ & $\begin{array}{l}0.457 \\
(0.65)\end{array}$ & -0.002 \\
\hline TED Spread Top 20\% & $\begin{array}{l}0.0441^{*} \\
(6.12)\end{array}$ & $\begin{array}{l}0.478 \\
(0.51)\end{array}$ & & $\begin{array}{l}0.0248 * \\
(4.29)\end{array}$ & $\begin{array}{l}1.508^{*} \\
(2.06)\end{array}$ & & $\begin{array}{l}0.0302 * \\
(5.24)\end{array}$ & $\begin{array}{l}1.594 * \\
(2.23)\end{array}$ & \\
\hline \multicolumn{10}{|c|}{$M O M_{J 1}-C T R_{J 2}{ }^{N O N-C t r}$ as dependent variable } \\
\hline TED Spread & $\begin{array}{l}0.0141 * \\
(2.05)\end{array}$ & $\begin{array}{l}0.851 \\
(0.85)\end{array}$ & -0.000 & $\begin{array}{l}0.0055 \\
(0.71)\end{array}$ & $\begin{array}{l}1.064 \\
(0.89)\end{array}$ & 0.001 & $\begin{array}{l}0.0126 \\
(1.73)\end{array}$ & $\begin{array}{l}0.375 \\
(0.36)\end{array}$ & -0.003 \\
\hline TED Spread Top 20\% & $\begin{array}{l}0.0371^{*} \\
(3.79)\end{array}$ & $\begin{array}{l}4.669 * \\
(3.75)\end{array}$ & & $\begin{array}{l}0.0440 * \\
(3.69)\end{array}$ & $\begin{array}{l}3.492 * \\
(2.29)\end{array}$ & & $\begin{array}{l}0.0474 * \\
(4.83)\end{array}$ & $\begin{array}{l}3.039 * \\
(2.47)\end{array}$ & \\
\hline \multicolumn{10}{|c|}{$\mathrm{MOM}_{I 1}-C T R_{I 2}{ }^{\text {NON-Mom\&Ctr }}$ as dependent variable } \\
\hline TED Spread & $\begin{array}{l}0.0067 \\
(1.79)\end{array}$ & $\begin{array}{l}0.115 \\
(0.20)\end{array}$ & -0.003 & $\begin{array}{l}0.0018 \\
(0.48)\end{array}$ & $\begin{array}{l}-0.179 \\
(-0.30)\end{array}$ & -0.003 & $\begin{array}{l}0.00276 \\
(0.71)\end{array}$ & $\begin{array}{l}0.0584 \\
(0.11)\end{array}$ & -0.003 \\
\hline TED Spread Top 20\% & $\begin{array}{l}0.0269 * \\
(3.87)\end{array}$ & $\begin{array}{l}1.709 * \\
(2.02)\end{array}$ & & $\begin{array}{l}0.0237 * \\
(5.67)\end{array}$ & $\begin{array}{l}0.781 \\
(1.62) \\
\end{array}$ & & $\begin{array}{l}0.0283^{*} \\
(3.87)\end{array}$ & $\begin{array}{l}0.807 \\
(0.86) \\
\end{array}$ & \\
\hline
\end{tabular}

This table reports the regression results of pure momentum/reversal and decomposed double-sort strategy returns on funding liquidity. The dependent variables are the double-sort strategy returns with contrarian or momentum (or both) removed and the independent variables are the TED spread and extremes. Panel A reports pure momentum and reversal whereas Panel B reports the results based on orthogonalized returns. In Panel A, MOM $M_{J-K}$ denotes single-sort momentum strategies and $C T R_{J-K}$ denotes single-sort contrarian/reversal strategies. The dependent variables are returns of pure momentum and contrarian strategies and the independent variables are the TED Spread and extremes. In Panel B, $M O M_{J 1}-C T R_{J 2}{ }^{N O N-M o m}$ and $M O M_{J 1}-C T R_{J 2}{ }^{\text {NON-Ctr }}$ denote the orthogonalized double-sort strategy with momentum or reversal removed, respectively. $M O M_{J_{1}}-C T R_{J 2}{ }^{\text {NON-Mom\&Ctr }}$ denotes the orthogonalized double-sort strategy with both momentum and reversal eliminated. According to the assumptions in Equation (1), $M O M_{J 1}-C T R_{J 2}{ }^{N O N-M o m \& C t r}$ can also be viewed as the interaction term between momentum and reversal. * denotes statistical significance at the $5 \%$ level or better. 
Table 10 Correlations of single and double sort strategies with traditional asset classes

\begin{tabular}{|c|c|c|c|c|c|c|}
\hline & GSCI & S\&P500 & T-bond & $\mathrm{FX}$ & T-bill & UMD \\
\hline \multicolumn{7}{|c|}{ Panel A: Single-sort strategy } \\
\hline $\operatorname{Mom}_{12-1}$ & $\begin{array}{r}0.2056^{*} \\
(0.00)\end{array}$ & $\begin{array}{r}0.0045 \\
(0.93)\end{array}$ & $\begin{array}{r}-0.0084 \\
(0.87)\end{array}$ & $\begin{array}{r}0.02 \\
(0.69)\end{array}$ & $\begin{array}{r}0.1045 * \\
(0.03)\end{array}$ & $\begin{array}{r}0.1475^{*} \\
(0.00)\end{array}$ \\
\hline \multicolumn{7}{|c|}{ Panel B: Double-sort strategies } \\
\hline $\operatorname{Mom}_{12}-\operatorname{Ctr}_{18}$ & $\begin{array}{r}0.0451 \\
(0.37)\end{array}$ & $\begin{array}{r}-0.0132 \\
(0.79)\end{array}$ & $\begin{array}{r}0.0789 \\
(0.12)\end{array}$ & $\begin{array}{r}-0.0459 \\
(0.36)\end{array}$ & $\begin{array}{r}0.065 \\
(0.19)\end{array}$ & $\begin{array}{r}0.062 \\
(0.21)\end{array}$ \\
\hline $\operatorname{Mom}_{12}-\mathrm{Ctr}_{24}$ & $\begin{array}{r}0.072 \\
(0.15)\end{array}$ & $\begin{array}{r}0.0261 \\
(0.60)\end{array}$ & $\begin{array}{r}0.0977 \\
(0.06)\end{array}$ & $\begin{array}{r}-0.0463 \\
(0.36)\end{array}$ & $\begin{array}{r}0.0957 \\
(0.06)\end{array}$ & $\begin{array}{r}0.0575 \\
(0.25)\end{array}$ \\
\hline $\operatorname{Mom}_{12}-\mathrm{Ctr}_{36}$ & $\begin{array}{r}0.0178 \\
(0.73)\end{array}$ & $\begin{array}{r}0.0098 \\
(0.85)\end{array}$ & $\begin{array}{r}0.0757 \\
(0.14)\end{array}$ & $\begin{array}{r}-0.0283 \\
(0.58)\end{array}$ & $\begin{array}{r}0.1086 * \\
(0.03)\end{array}$ & $\begin{array}{r}0.0447 \\
(0.38)\end{array}$ \\
\hline Absolute Average & 0.0450 & 0.0076 & 0.0841 & -0.0402 & 0.0804 & 0.0547 \\
\hline
\end{tabular}

This table reports the Pearson correlations and $p$-ratios. Mom ${ }_{\mathrm{J}-1}$ denotes the single-sort momentum strategy and $\mathrm{Mom}_{\mathrm{J} 1}-$ $\mathrm{Ctr}_{\mathrm{J} 2}$ represents the double-sort momentum and contrarian strategies. GSCI, S\&P500 and T-Bond represent the excess return of S\&P GSCI, S\&P 500 and U.S. Government Bond Index, respectively. FX denotes the U.S. dollar effective exchange rate and T-bill is the yield on the three-month U.S. Treasury Bill. UMD represents the Fama-French crosssectional momentum factor in the U.S. equities market. * denotes statistical significance at the $5 \%$ level or better. The absolute average of correlation of all double-sort strategies in each market is also reported.

Table 11 Performance of double-sort momentum strategies over an extended sample

\begin{tabular}{lrrrr} 
& Mom $_{12}-\mathrm{Ctr}_{18}$ & Mom $_{12}$-Ctr 24 & Mom $_{12}-\mathrm{Ctr}_{36}$ & Mom $_{12-1}$ \\
\hline Panel A: Long Portfolio & & & & \\
Annualized arithmetic mean & 0.1709 & 0.1586 & 0.1221 & 0.1101 \\
t-statistics & 4.18 & 3.37 & 2.68 & 3.13 \\
Annualized volatility & 0.2295 & 0.2633 & 0.2557 & 0.2139 \\
Reward/Risk Ratio & 0.7447 & 0.6022 & 0.4777 & 0.5147 \\
Sortino Ratio & 1.2935 & 1.06 & 0.8013 & 0.8455 \\
Skewness & 1.0867 & 1.9012 & 1.4003 & 0.5551 \\
Kurtosis & 9.8117 & 17.69 & 14.5489 & 9.8533 \\
& & & & \\
Panel B: Short Portfolio & & & & \\
\hline Annualized arithmetic mean & -0.0783 & -0.0499 & -0.0672 & -0.0373 \\
t-statistics & -2.7 & -1.57 & -2.05 & -1.38 \\
Annualized volatility & 0.1815 & 0.1948 & 0.1998 & 0.1642 \\
Reward/Risk Ratio & -0.4312 & -0.2559 & -0.3362 & -0.227 \\
Sortino Ratio & -0.6107 & -0.3649 & -0.4754 & -0.3388 \\
Skewness & -0.1387 & -0.1818 & -0.2913 & 0.0461 \\
Kurtosis & 6.0995 & 6.3686 & 6.8551 & 6.6689 \\
& & & & \\
Panel C: Long-Short Portfolio & & & & \\
\hline Annualized arithmetic mean & 0.2492 & 0.2085 & 0.1893 & 0.1474 \\
t-statistics & 5.72 & 4.18 & 3.86 & 4.12 \\
Annualized geometric mean & 0.2309 & 0.1737 & 0.1579 & 0.1245 \\
Annualized volatility & 0.2532 & 0.2857 & 0.2834 & 0.2172 \\
Annualized downside volatility & 0.1357 & 0.1501 & 0.1495 & 0.1265 \\
Reward/Risk Ratio & 1.0596 & 0.7643 & 0.7116 & 0.6785 \\
Sortino Ratio & 1.977 & 1.4551 & 1.3491 & 1.247 \\
Skewness & 0.8013 & 1.5103 & 1.3094 & 0.6775 \\
Kurtosis & 5.9611 & 11.9532 & 9.7675 & 6.9968 \\
Max monthly gain & 0.4079 & 0.6161 & 0.5543 & 0.397 \\
Max monthly loss & -0.2046 & -0.244 & -0.2046 & -0.1780 \\
\hline
\end{tabular}

This table reports the performance of the double-sort strategy over an extended sample period. Panels A and B summarize the long and short portfolios, respectively, whereas Panel C reports the long-short portfolio. These double-sort strategies are benchmarked against their respective single-sort momentum strategies. The sample period covers the period 1977 to 2014 and includes 27 S\&P commodity futures. 

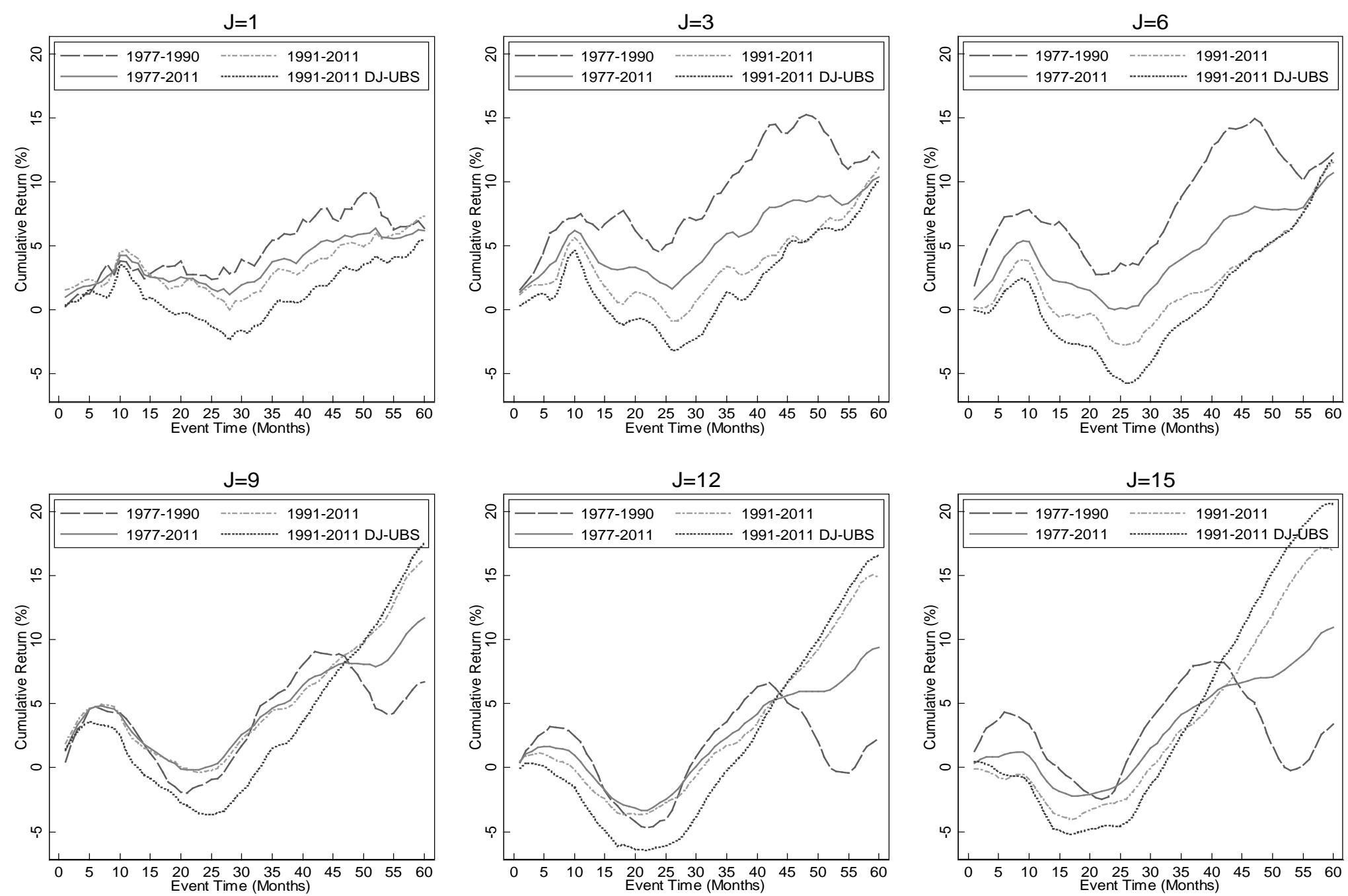

\section{Figure 1 Cumulative momentum profits}

This figure illustrates the cumulative momentum portfolio returns with 27 GSCI and 26 UBS commodity futures. $J$ represents the ranking period. The $\mathrm{x}$-axis shows the post-formation event months. The $y$-axis indicates the cumulative portfolio return. The post-formation period starts from 1 to 60 months. Two sub-samples are presented in the 1977-2011 period, with the second subperiod beginning in 1991. 
All excl. Agriculture
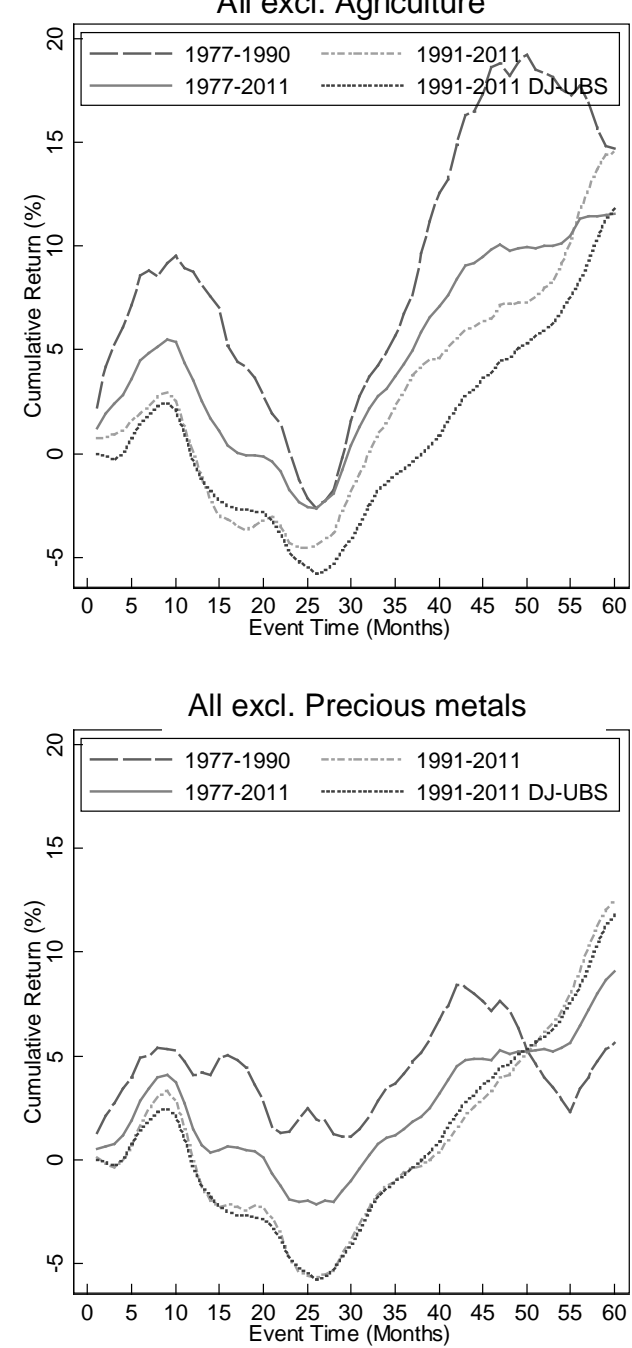

All excl. Energy

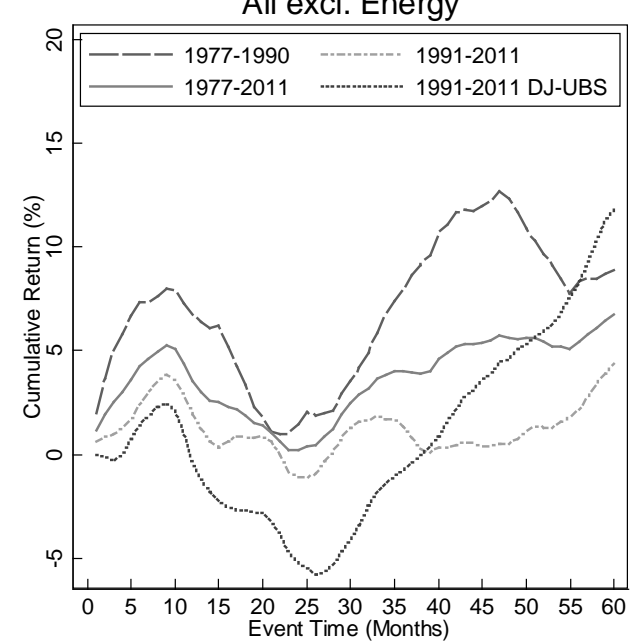

All excl. Industrial metals

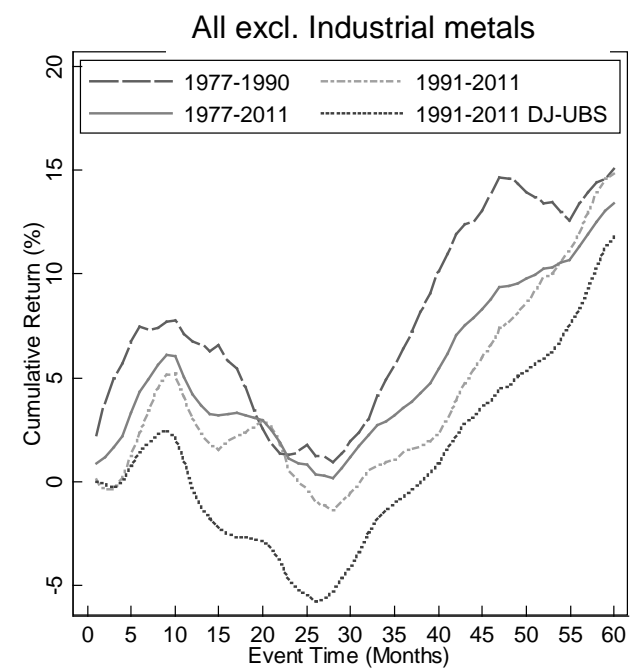

All excl. Livestock

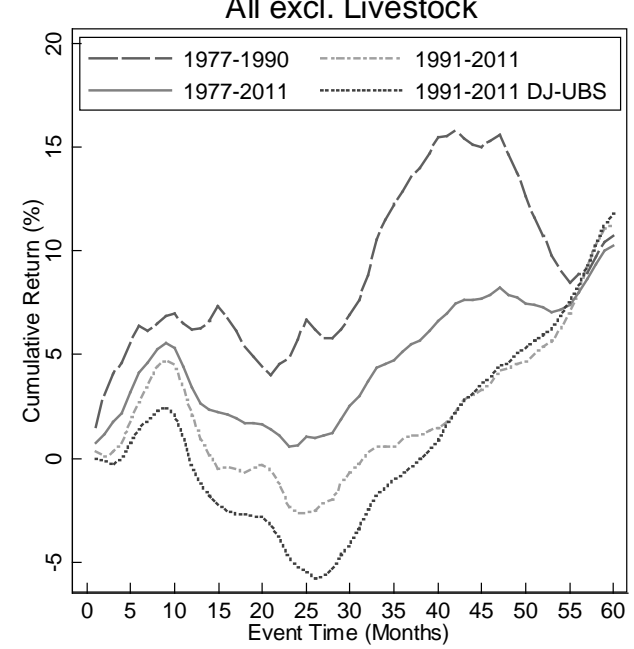

20
Event Time (Months)

\section{Figure 2 Sub-sector cumulative return post-formation $J=6$}

This figure illustrates the cumulative momentum portfolio returns with 27 GSCI and 26 UBS commodity futures. $J$ represents the ranking period. The x-axis shows the post-formation event months. The y-axis indicates the cumulative portfolio return. The post formation period is from 1 to 60 months. Two sub-samples are presented in the 1977-2011 period, with the second sub-period beginning in 1991. One commodity sector is excluded at a time. 
Figure 3 Three-dimensional plot of the performance of double-sort momentum-contrarian strategies

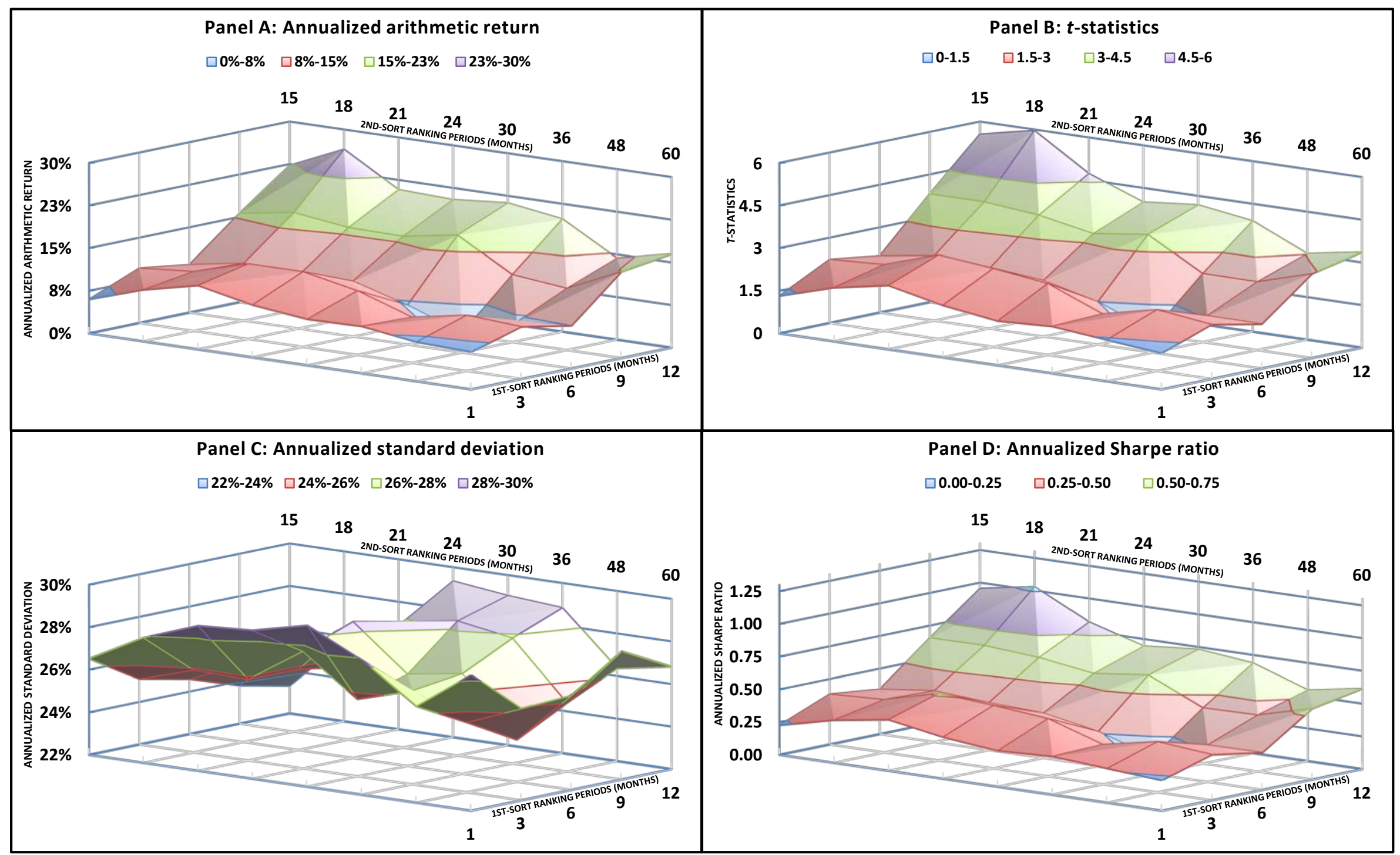

This figure presents a 3D plot of the performance of 40 double-sort momentum-contrarian strategies. Panel A illustrates the annualized return whereas Panel B exhibits the associated $t$-statistics. Panels C and D plot the annualized standard deviation and Sharpe ratios, respectively. The $\mathrm{x}$-axis outlines the ranking periods for the second-sort reversal signal and the z-axis outlines the ranking periods for the first sort momentum signal. The y-axis reports the respective statistics in each panel. 


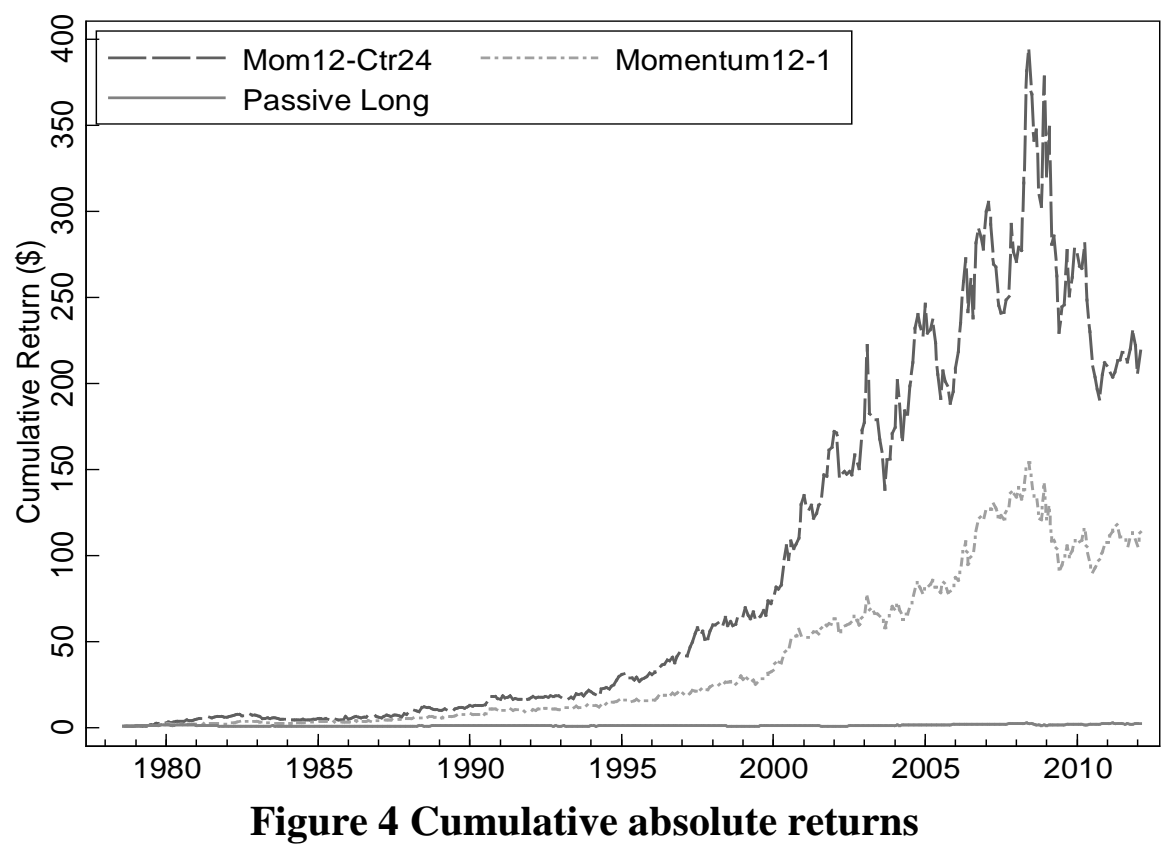

This figure illustrates the cumulative dollar return of a passive long, single-sort momentum strategy (Mom ${ }_{12-1}$ ) and double-sort momentum/contrarian strategy ( $\mathrm{Mom}_{12}-\mathrm{Ctr}_{24}$ ). The test period is from 1977 to 2011. The solid line reports the performance of a passive long equal weighted portfolio of $27 \mathrm{~S} \& \mathrm{P}$ commodities. The short dashed line illustrates the 12-month single-sort momentum strategy with a holding period of one month. The long dashed line reports the double-sort strategy with a 12-month momentum signal as the first sort and a 24-month contrarian signal as the second sort.

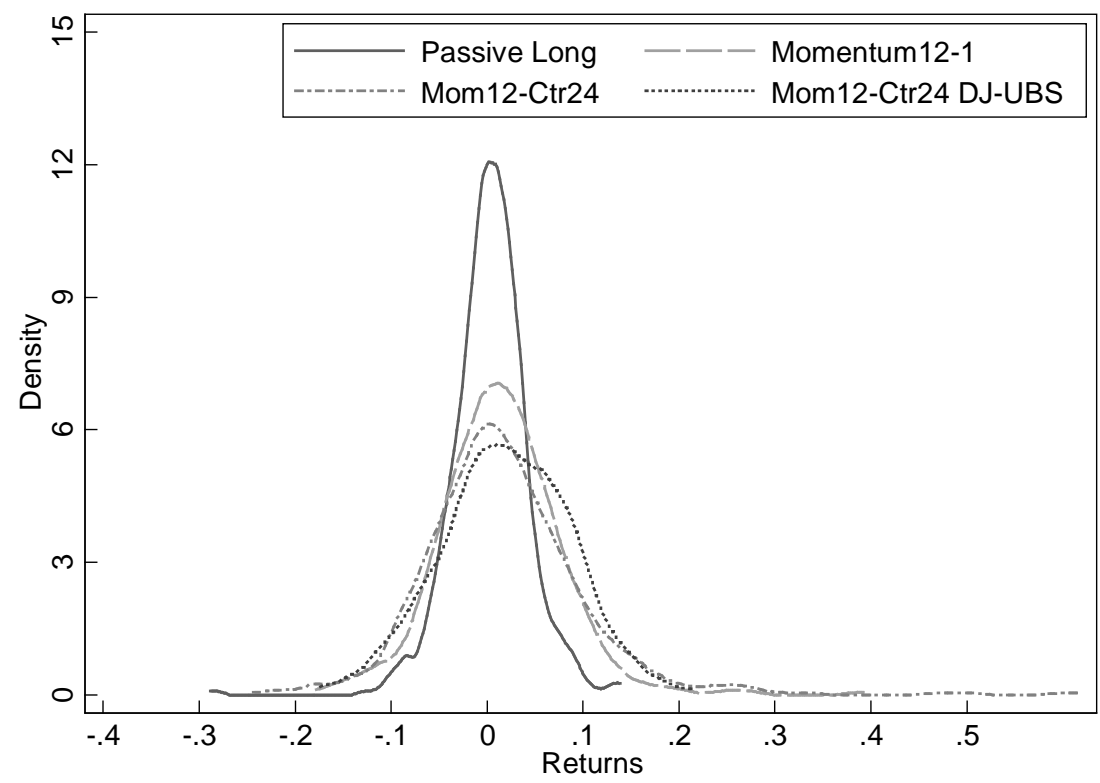

Figure 5 Returns distribution

This figure illustrates the return distributions of the passive long, single-sort momentum strategy (Mom $12-1)$ and double-sort momentum and contrarian strategies (Mom $\left.{ }_{12}-\mathrm{Ctr}_{24}\right)$. The sample covers 1977 to 2011 and 1991 to 2011 with the UBS data set. The solid line reports the passive long portfolio of all 27 S\&P commodity futures. The short dashed line illustrates the 12-month single-sort momentum strategy with a holding period of one month. The long dashed line is the double sort strategy with the 12-month momentum signal as the first sort and 24-month reversal signal as the second sort. The small dotted line reports the double-sort strategy based on the UBS data set. 


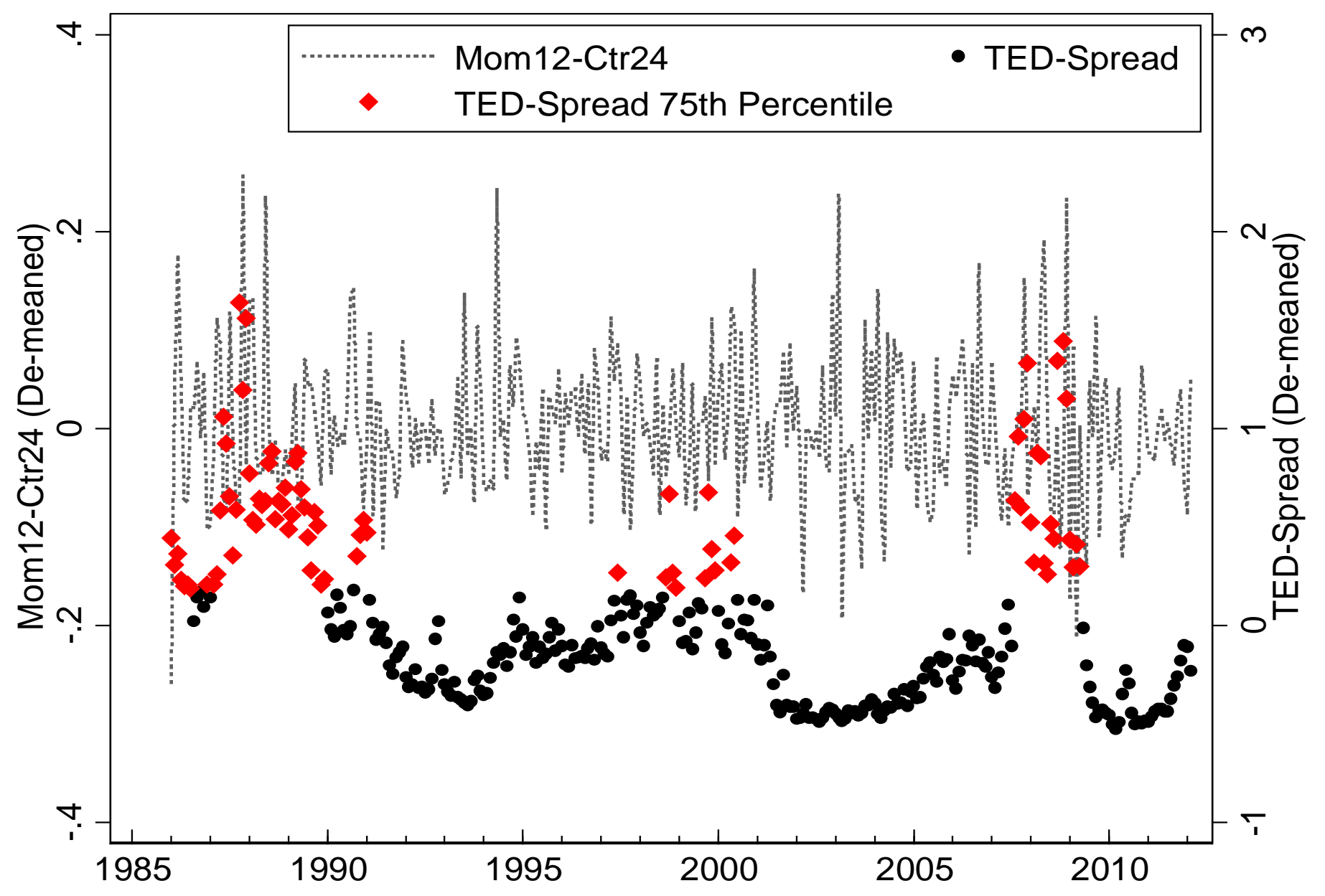

Figure 6 TED Spread and Mom12-Ctr24 excess return plot (de-meaned)

This figure plots the excess return of the double-sort strategy ( $\left.\mathrm{Mom}_{12}-\mathrm{Ctr}_{24}\right)$ against the global funding liquidity (TED-spread) from 1986 to 2011. Both TED spread and $\mathrm{Mom}_{12}-\mathrm{Ctr}_{24}$ are de-meaned. The dotted line represents the double-sort strategy, the circle and diamond plots depict the TED spread where diamond plots highlight the highest quartile observations. The primary y-axis indicates the former and the secondary y-axis indicates the latter. 
Appendix 1 Data-snooping test for strategy superiority

\begin{tabular}{lrrr}
\hline Bootstrap Dependence & Bootstrap Method & $\begin{array}{r}\text { Reality Check } \\
\text { Consistent } p \text {-values }\end{array}$ & $\begin{array}{r}\text { SPA test } \\
\text { Consistent } p \text {-values }\end{array}$ \\
\hline
\end{tabular}

Panel A: All strategies versus passive long benchmark

$\begin{array}{llll}q=0.05 & \text { Stationary } & 0.0336 & 0.0341 \\ & \text { Circular } & 0.0362 & 0.0388 \\ q=0.1 & \text { Stationary } & 0.0487 & 0.0456 \\ & \text { Circular } & 0.0479 & 0.0420 \\ & \text { Stationary } & 0.0729 & 0.0751 \\ & \text { Circular } & 0.0733 & 0.0705\end{array}$

Panel B: All single-sort strategies versus passive long benchmark

\begin{tabular}{llll}
$q=0.05$ & Stationary & 0.0350 & 0.0366 \\
& Circular & 0.0349 & 0.0358 \\
\multirow{2}{*}{$q=0.1$} & Stationary & 0.0442 & 0.0479 \\
& Circular & 0.0417 & 0.0470 \\
& Stationary & 0.0706 & 0.0762 \\
& Circular & 0.0762 & 0.0688
\end{tabular}

Panel C: All double-sort strategies versus passive long benchmark

$\begin{array}{llll}q=0.05 & \text { Stationary } & 0.0000 & 0.000 \\ & \text { Circular } & 0.0000 & 0.000 \\ q=0.1 & \text { Stationary } & 0.0000 & 0.000 \\ & \text { Circular } & 0.000 & 0.0000 \\ & \text { Stationary } & 0.0000 & 0.000\end{array}$

Panel D: All double-sort strategies versus Momentum 12-1 $_{\text {benchmark }}$

\begin{tabular}{|c|c|c|c|}
\hline \multirow[t]{2}{*}{$q=0.05$} & Stationary & 0.0000 & 0.000 \\
\hline & Circular & 0.0000 & 0.000 \\
\hline \multirow[t]{2}{*}{$q=0.1$} & Stationary & 0.0000 & 0.000 \\
\hline & Circular & 0.0000 & 0.000 \\
\hline \multirow[t]{2}{*}{$q=0.5$} & Stationary & 0.0000 & 0.000 \\
\hline & Circular & 0.0000 & 0.000 \\
\hline
\end{tabular}

This table reports the Reality Check (White, 2000) and SPA (Hansen, 2005) test consistent p-values for superior performance. The parameter $q$ is the geometric distribution that determines the block-length in the bootstrap samples, where the expected block length is given by $1 / q$. The consistent (not pairwise) $p$-values are reported for both the RC and SPA tests. For each test, the bootstrap is replicated 10,000 times. The stationary and circular bootstraps are based on Politis and Romano (1994) and Politis and Romano (1992), respectively. There are in total 25 strategies, which include 13 single-sort and 12 double-sort strategies. Panel A reports all strategies against the equal-weighted longonly benchmark. Panel B reports 13 single-sort strategies against the passive benchmark and Panel C reports 12 double-sort strategies against the benchmark. Panel D reports 12 double-sort strategies against the most profitable single-sort active strategy as the benchmark. Significant $p$-values indicate that the strategies outperform the benchmark. 